\title{
Numerical investigation of the influence of discontinuity orientations on fault permeability evolution and slip displacement
}

\author{
Dorcas S. Eyinla (D) Quan Gan • Michael A. Oladunjoye • Abel I. Olayinka
}

Received: 13 May 2020/Accepted: 6 April 2021/Published online: 23 April 2021

(C) The Author(s) 2021

\begin{abstract}
A pre-existing plane of weakness along the fault is comprised of a particular pattern of joints dipping at different orientations. The fault stress state, partially defined by the orientation of fault, determines the potential of slip failure and hence the evolution of fault permeability. Here the influence of fault orientation on permeability evolution was investigated by direct fluid injection inside fault with three different sets of fault orientations $\left(45^{\circ}, 60^{\circ}\right.$ and $\left.110^{\circ}\right)$, through the coupled hydromechanical (H-M) model TOUGHREACT-FLAC3D. The influence of joints pattern on slip tendency and magnitude of potential induced seismicity was also evaluated by comparing the resulted slip distance and timing. The simulation results revealed that decreasing the dip angle of the
\end{abstract}

D. S. Eyinla $(\bowtie) \cdot$ M. A. Oladunjoye · A. I. Olayinka Department of Geology, Pan African University, Life and Earth Sciences Institute (PAULESI), University of Ibadan, Ibadan, Nigeria

e-mail: dorcas.eyinla@aaua.edu.ng

D. S. Eyinla

Department of Earth Sciences, Adekunle Ajasin

University, Akungba Akoko, Nigeria

D. S. Eyinla · Q. Gan

Department of Petroleum Geology and Geology, School of Geosciences, University of Aberdeen, Aberdeen,

Scotland, UK

Q. Gan

College of Resources and Safety Engineering, Chongqing

University, Chongqing, China fault increases the corresponding slip tendency in the normal fault circumstance. Also, with changing joints dip angle associated with the fault, the tendency of the fault slip changes concurrently with the permeability evolution in a noticeable manner. Permeability enhancement after the onset of fault slip was observed with the three sets of fault angles, while the condition of $60^{\circ}$ dipping angle resulted in highest enhancement. Joints pattern with a dip angle of $145^{\circ}$ (very high dip) and $30^{\circ}$ (very low dip) did not trigger a shear slip with seismic permeability enhancement. However, high dip and intermediate dip angles $\left(135^{\circ}, 50^{\circ}\right.$ and $70^{\circ}$ ) yielded high permeability in varying orders of magnitude. The large stress excitation and increasing permeability during shear deformation was noticeably high in intermediate joint dip angles but decreases as the angle increases.

\section{Article highlights}

1. The magnitude of injection-induced permeability enhancement is largely influenced by the fault and joint spatial orientations.

2. With a slight change in the joint direction, there is an increasing possibility for fault to approach a different critical state of failure.

3. Stress elevation at the point of failure is controlled by the orientations of fault/joint planes with respect to the direction of maximum principal stress. 
Keywords Permeability evolution · Joint shear strength $\cdot$ Frictional resistance $\cdot$ Joint dip patterns . Fault/joint orientation $\cdot$ Slip tendency

\section{Introduction}

The quest for enhanced recovery from tight reservoirs requires a detailed study of several factors such as reservoir quality, natural fracture networks, orientation of the fractures, geomechanical properties of the matrix rock and fractures. Faults and fractures are the main targets in field development plan that enable production in naturally fractured reservoirs or induced hydraulic fractures in tight reservoirs, which practically makes fault permeability evolution study a crucial investigation in production optimization (Nelson 1985). However, this scientific study becomes more valid when variations in fault orientation and the direction of associated joints are considered in the simulation process, as this factor would strongly influence permeability anisotropy in fractured reservoirs (Watkins et al. 2018). The rapid increase in energy production has been enabled by the means of new technological advancement, such as multistage hydraulic-fracture stimulation (Rutqvist et al. 2015). Nevertheless, there are several concerns relating to the adoption of these new technologies in terms of variabilities in fault properties yielding a wide range of results (for instance, the permeability evolution as injection conditions change). Additionally, studies need to ascertain whether the injection has potential for fault reactivation, and in what magnitude is the accompanying seismicity (Davies et al. 2013; Rutqvist et al. 2013, 2015).

From reports (e.g. Shrivastava and Lawatia 2011; Xue et al. 2014; Wang et al. 2016; Feng et al. 2018; Eyinla et al. 2021), tight reservoirs have specific variations from the conventional reservoirs because of certain factors which include high heterogeneity, their deeper depth of burial, diagenetic properties, low porosities, very low permeability, poorly developed fracture system and abnormal pressure with. While rocks contain different forms of discontinuities which play an inevitable role in the overall mechanical and elastoplastic behaviour, the most significant types of discontinuities in rocks include faults, fractures, weak planes/joints, shear zones, planes of foliation, bedding planes and planes of cleavage (Eshiet and Sheng 2017). Their properties are complex, and several investigations have been carried out to assess some of their behavioural characteristics in the matrix (Brown 1987; Fairhurst 2013; Eshiet and Sheng 2017; Ghosh et al. 2018). Discontinuities influence and alter the total behaviour of rocks under in-situ and laboratory conditions. These effects are however dependent on the properties of the fault and joints, the geometry and quantity, which are also related to the locations in which they are situated in the medium. However, where two or more joints are present, the effects become more prominent, therefore, how the joints affect the behaviour of the rock is often attributed to their lower strength in comparison with the host rock (matrix) and their large-scale anisotropic properties (Eshiet and Sheng 2017).

Hydraulic fracturing via injection has become a standard technique for improving the permeability of tight reservoir in oil and gas development. However, discontinuities developed from such a process often disturb and divert hydraulic fracture propagation and path, therefore, distorting fracture fluid flow and proppant transport (Watkins et al. 2018). Consequently, the prediction of fracture/joint behaviour at varying geometry becomes an important study. Although the initiation of cracks along joint planes is mostly induced by shear failure; however, the resulting fracture reactivation is predominantly attributed to the tensile failure of the rock material (Eshiet and Sheng 2017). An essential factor which also determines the quality and yield of tight reservoirs is the distribution of fracture-controlled permeability resulting from fluid injection, which could be attributed to several factors such as the pattern of joints. Nonetheless, one way of characterizing these fractures is by the application of numerical forward modeling (Parker 2013) and laboratory experiments (Asahina et al. 2018; Feng et al. 2018). The combination of both would give a more detailed study and allows adequate scientific correlation. Field developments now involve the adoption of improved static reservoir characterization method, which incorporates essentially the geomechanical properties of the field and the initial stress distribution on the reservoir, including the numerical reservoir modeling which examines the dynamic evolution of stress state during fault injection (Turner et al. 2017). 
Studies have shown that the spatial distribution and orientation of fault may or may not be the same as the associated joints (Cappa and Rutqvist 2011), but the existence of these discontinuities in different forms have an intrinsic influence on the numerical simulation for thermo-hydro-mechanical interactions. On a wider scale, it determines the expected hydraulic fractures emerging, and the overall recovery process (Men et al. 2018). Many numerical and analytical solutions to both hydraulic fracturing problem and Enhanced Geothermal Systems have been proposed, and each of these has improved the understanding of the thermo-hydro-mechanical response of fault under injection, especially when it considers the influence of fracture geometry (Adachi et al. 2007; Rutqvist et al. 2013, 2015; Yang and Zoback 2014; Jacquey et al. 2015; Gan and Elsworth 2016a; Feng et al. 2018). Additionally, many studies have reported field experiments and laboratory studies of hydraulic fracture behaviour in both large and small scales (Blair et al. 1989; Legarth et al. 2005; Roberts 2005; Casas et al. 2006; Athavale and Miskimins 2008; Roberts and Abdel-Fattah 2009; Liu and Manga 2009; Chuprakov et al. 2010; Elkhoury et al. 2011; Faoro et al. 2012; Candela et al. 2014). From these reports, permeability enhancement mechanism is characterized by dynamic stresses induced by fluid pressure.

The study conducted by Gan and Elsworth (2016a) explored a diverse stimulation scheme to determine the impact of stimulation direction relative to the fracture orientations on the magnitude and extent of thermal recovery rates, for a proposed reservoir with a defined pre-existing fracture network. However, to create a discrete fracture network in a simulation, several factors are often considered, which include, fracture location, the orientation, length, and fracture aperture (Gan and Elsworth 2016b). Cappa and Rutqvist (2011) reported that the most important factors for the initiation of fault slip are shear stress development and fluid pressure, as they are known to enhance fault rupture by overcoming the fault frictional resistance. Consequently, for any numerical study, slip-tendency analysis provides a technique which allows scientific evaluation of stress states and how it can be related to expected seismic or aseismic activity. Resistance to frictional sliding has been identified as a factor which is responsible for the slip behaviour of faults during fluid injection (Jacquey et al. 2015), and it is influenced by the properties of the associated joints (Zhang et al. 2018).

Generally, during unloading of fault (reduction in the normal stress), hysteresis in the fracture permeability is often observed. This implies that fault permeability is usually noticeably different during unloading from the loading phase even when they are stressed equally (Gutierrez et al. 2000). The hysteretic property of the fault permeability under normal loading simply connotes a manifestation of the general irreversibility of rock deformation (Lavrov 2017). However, concerning the simple relationship between fractures, stress and strain during injection, contributions from many studies have presented theories, numerical approach and analysis of injection-induced fault reactivation and seismic slip (e.g. Adachi et al. 2007; Rutqvist et al. 2013, 2015; Yang and Zoback 2014; Gan and Elsworth 2014, 2016b; Jacquey et al. 2015). These and many more reports have enhanced the understanding of the fault reactivation processes, especially in enhanced geothermal systems. However, because of the role played by fault orientations in the stress field analysis, variations in fault permeability with respect to the changing fracture/joint orientations can now be explained through numerical simulations. An example of these studies was earlier presented by Jacquey et al. (2015), demonstrating how the angle of fault influences the initial slip tendency and dynamic permeability evolution. It is crucial to understand how permeability changes during shear deformation, as this would afford an understanding of the dynamic hydromechanical processes during injection and mechanisms influencing the occurrence of earthquakes both at shallow and in deep crustal levels (Tanikawa et al. 2010).

Thus, this study explores the roles of fault geometry and associated joints, using data from tight shale reservoir from Akas field of the Niger Delta Basin as a case study. Studies from this field have been discussed in previous reports (Eyinla and Oladunjoye 2019; Eyinla et al. 2020, 2021). The reservoir model is presented as a finite medium with a hydraulically induced normal fault, and the overall mechanical behaviour of fault is represented by a set of solid elements with ubiquitous joints which are oriented as weak planes in the fault zone as described by Cappa and Rutqvist (2011). We investigate how their relationship could modify the poroelastic response of the fault under undrained simulation conditions. In 


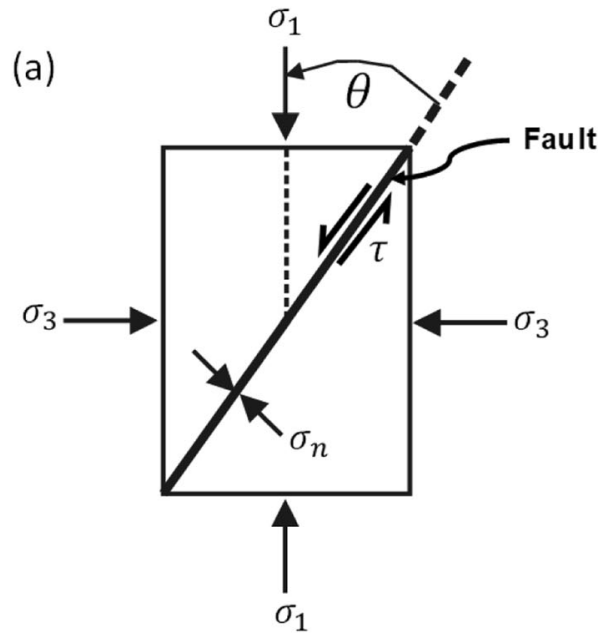

Fig. 1 a Resolution of normal and stresses along a fault plane with a given orientation from the remote principal stresses (modified from Cappa and Rutqvist 2011), b Shear stress against

overall, the study seeks to understand the response of fault slip behaviour during injection as orientational properties change for the purpose of production optimization, reservoir management and prediction of seismic event.

\section{Theory of study and methodology}

\subsection{Stress theory}

The effective normal stress and the shear stress acting on a fault (Fig. 1a) are estimated from the generated data after simulation, using the approach modified after Gan and Elsworth (2014) with the parameters in Fig. 1a thus:

$$
\begin{aligned}
& \sigma_{\mathrm{n}}=\frac{\sigma_{3}+\sigma_{1}}{2}+\frac{\sigma_{3}-\sigma_{1}}{2} \cos 2 \theta+\tau_{\mathrm{xz}} \sin 2 \theta-\mathrm{P} \\
& \tau=\frac{\sigma_{1}-\sigma_{3}}{2} \sin 2 \theta+\tau_{\mathrm{xz}} \cos 2 \theta
\end{aligned}
$$

where $\sigma_{\mathrm{n}}$ represents the effective normal stress, $\mathrm{P}$ is the pore fluid pressure, $\sigma_{1}$ is the maximum principal stress, $\sigma_{3}$ is the minimum principal stress and $\theta$ represents the angle between the fault plane and the maximum principal stress, $\sigma_{1}$ direction.

Therefore, Coulomb stress ratio, $\eta$, which is defined as the ratio of shear stress to effective normal stress (Fig. 1b) is represented as: (b)

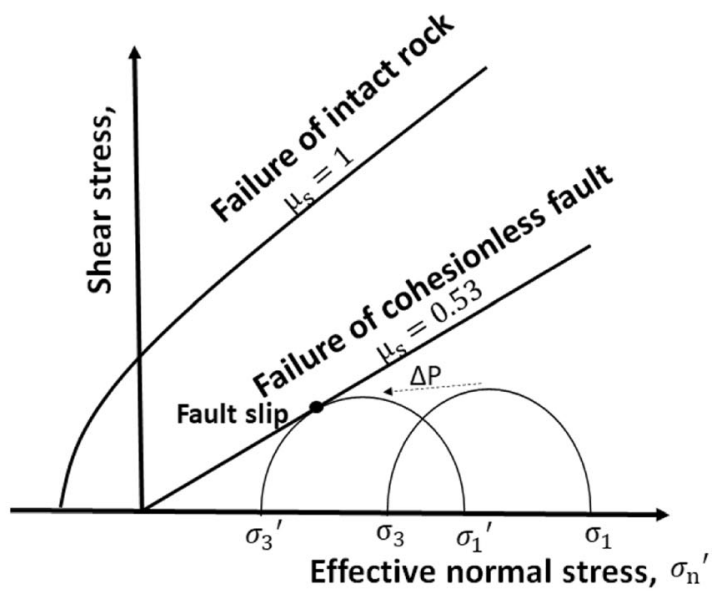

effective normal stress showing slip failure mechanism by fluid pressurization (modified from Gan and Elsworth 2014)

$\eta=\frac{\tau}{\sigma_{\mathrm{n}}}$

Notably, for any surface, the slip tendency can be described as the ratio of acting shear stress $(\tau)$ to the effective normal stress $\left(\sigma_{\mathrm{n}}\right)$. However, a slip is likely to occur on the surface when this ratio is greater than or equal to the frictional resistance to sliding (Jaeger et al. 2009). Also, the static friction coefficient, $\mu_{\mathrm{s}}$, has been defined by Biot (1941) and Byerlee (1978) as:

$\mu_{\mathrm{s}}=\tan \phi$

where $\phi$ is the friction angle. And for this study, the internal fault friction angle used is $28^{\circ}$, consequently, the coefficient of friction, $\mu_{\mathrm{s}}=0.53$. Therefore, for a slip to occur, the maximum coulomb stress ratio value (called the peak friction) must be greater than or equal to $0.53\left(\eta=\tau / \sigma_{n} \geq \mu_{s}\right)$. Thus, the reactivation of a pre-existing fault is likely to occur during fluid injections, depending on the maximum sustainable pressure limit and principal stress resolution (Kim and Hosseini 2014).

\subsection{Fault permeability and aperture evolution}

In this model, a demonstration of the sensitivity of fault permeability to hydromechanical interactions, normal stress change as well as volumetric strain is presented. The behavior of the fault would undoubtedly influence a change in the fault normal 
displacement. Consequently, sudden increase in the fault permeability would result at the onset of shear slip (Eyinla et al. 2020). For a fractured medium, models for permeability change as governed by the input variables involves the growth in the fracture aperture, which may be defined by an exponential function of applied effective stress $\sigma$ and the nonlinear fracture stiffness $\alpha$ (Rutqvist et al. 2002; Gan and Elsworth 2014) given as:

$b=b_{r}+\left(b_{\max }-b_{r}\right) e^{\left(-\alpha\left(\sigma^{1}-\sigma_{0}^{1}\right)\right)}$

where $b$ is the current hydraulic aperture due to current effective normal stress, $\sigma_{n}^{1}$, br is the residual aperture, $b_{\text {max }}$ is the maximum aperture without mechanical stress effect, $\sigma_{0}^{1}$ is the effective stress at which zero deformation occurs (usually 0 ), $\alpha$ is the non-linear fracture stiffness. Generally, the permeability of the fault damage zone is better presented when the pattern of the fracture is well defined, which however requires assigning the right aperture and fracture spacing. As a result, the initial permeability of the fault zone is higher than the permeability of the matrix (Table 1), and the transmissivity of fluid pressure within the fault zone is related to the hydraulic aperture of the fracture (Norbeck and Horne 2015). However, to satisfy the requirement for representing a coupled non-linear elastic behaviour of fault, the permeability of fractures in the fault zone has been modelled using existing approach (Warren and Root 1963) as it connects the fracture aperture and fracture spacing through the relation:

$\mathrm{k}=\frac{\mathrm{b}^{3}}{12 \mathrm{~s}}$

where $\mathrm{k}$ is the fault permeability $\left(\mathrm{m}^{2}\right), \mathrm{b}$ is the fracture aperture $(\mathrm{m})$, and $\mathrm{s}$ is the fracture spacing $(\mathrm{m})$.

\subsection{Mechanism of shear failure and seismic slip}

The fundamental mechanism of fault reactivation is expressed when the shear stress exceeds the shear strength of the fault (Cappa and Rutqvist 2011). Slip tendency is therefore regarded as the likelihood of a surface to slip during injection, a mechanism which is highly dependent on the frictional resistance of the fault and measured by the ratio of shear to normal stress acting on the fault plane (Fig. 1b). Analysis of stress distribution on the fault plane relative to the shear strength provides an understanding of its potential to cause a slip, and thus, makes it possible to evaluate general exploration risks, including seismicrisk, fault-rupture risk assessment and earthquake forecasting (Morris et al. 1996). The commonly used relationship describing fault slip in the failure analysis
Table 1 Material properties used for the simulation

\begin{tabular}{llll}
\hline Parameter [symbol (unit)] & Host rock & Fault damage zone & Fault core \\
\hline Bulk modulus $(\mathrm{GPa})$ & 15 & 1.5 & 1.5 \\
Poisson's ratio & 0.304 & 0.304 & 0.304 \\
Joint tensile strength $(\mathrm{MPa})$ & - & 0.04 & 0.04 \\
Porosity $\left(\emptyset_{\mathrm{m}}\right)$ & 0.01 & 0.30 & 0.30 \\
Initial permeability $\left[\mathrm{k}_{\mathrm{m}}\left(\mathrm{m}^{2}\right)\right]$ & $1 \times 10^{-16}$ & $1 \times 10^{-14}$ & $1 \times 10^{-15}$ \\
Thermal expansion coefficient of solid $\left.\left(\mathrm{K}^{-1}\right)\right]$ & $12 \times 10^{-6}$ & $12 \times 10^{-6}$ & $12 \times 10^{-6}$ \\
Rock density $\left(\mathrm{kg} / \mathrm{m}^{3}\right)$ & 2700 & 2700 & 2700 \\
Heat capacity of fluid $\left[\mathrm{c}_{\mathrm{w}}(\mathrm{J} / \mathrm{kg} \mathrm{K})\right]$ & $4.26 \times 10^{5}$ & $4.26 \times 10^{5}$ & $4.26 \times 10^{5}$ \\
Joint friction angle, dilation angle $\left(^{\circ}\right)$ & - & 28 & 28 \\
Cohesion $(\mathrm{MPa})$ & 3 & 0 & 0 \\
Dilation angle $\left({ }^{\circ}\right)$ & 0 & 5 & 5 \\
Non-linear stiffness & - & 0.218 & 0.218 \\
Maximum aperture, $(\mathrm{m})$ & - & $1.52 \times 10^{-4}$ & $1.47 \times 10^{-4}$ \\
Residual aperture, $(\mathrm{m})$ & - & $3.03 \times 10^{-5}$ & $2.95 \times 10^{-5}$ \\
Joint cohesion, $\mathrm{MPa}$ & 45 & 0 & 0 \\
Matrix friction angle, $\left({ }^{\circ}\right)$ & - & 45 & 45 \\
${\text { Joint friction angle }\left({ }^{\circ}\right)}$ & - & 28 & 28 \\
\hline
\end{tabular}


of a fault with a specified orientation is given as (Scholz 2019):

$\tau=\mathrm{c}+\mu_{\mathrm{s}} \sigma_{\mathrm{n}}^{\prime}$

And according to the Terzaghi (1923), the effective stress is expressed as:

$\sigma_{\mathrm{n}}^{\prime}=\sigma_{\mathrm{n}}-\mathrm{P}$

where $\tau$ is the critical shear stress for slip occurrence, $\mathrm{c}$ is the cohesion, $\mu_{\mathrm{s}}$ is the static friction coefficient, $\sigma_{\mathrm{n}}^{\prime}$ is the effective normal stress, $\sigma_{\mathrm{n}}$ is the total normal stress and $\mathrm{P}$ is the fluid pressure.

An approach to distinctly determine the fault stability and if a failure has occurred on a fault plane dipping in the vertical direction has been presented by Rutqvist and Oldenburg (2007) and Jaeger et al. (2009). This is examined by comparing the ratio of the maximum and minimum principal effective stresses with the frictional resistance as:

$\frac{\sigma_{1}^{\prime}}{\sigma_{3}^{\prime}}=\frac{\sigma_{1}-\alpha p}{\sigma_{3}-\alpha p} \leq \mathrm{q}$

Here, q represents the effective stress limiting ratio according to Biot effective stress theory (Biot 1941), and is defined as,

$\mathrm{q}=\left[\left(\mu_{\mathrm{s}}^{2}+1\right)^{1 / 2}+\mu_{\mathrm{s}}\right]^{2}$

where $\mu_{\mathrm{s}}=0.53$, (from Eq. 6), the value of $q=2.76$. In the initial setting of the model, $\alpha$ is the Biot coefficient sets at 1.0, $\sigma_{1}=45.5 \mathrm{MPa}$, $\sigma_{3}=27.3 \mathrm{MPa}$ and $\mathrm{P}=13.8 \mathrm{MPa}$, therefore, $\sigma_{1}^{\prime} / \sigma_{3}^{\prime}=2.3$. Consequently, the initial status of the fault is stable since $2.3<\mathrm{q}=2.76$.

\subsection{Estimating seismic magnitude}

Magnitude of seismic events in the fault zone as a result of fluid injection can be quantified using seismological theories and adopting the approach of Cappa and Rutqvist (2011) and Mazzoldi et al. (2012). This is based on a moment magnitude scale which describes the strength of the seismic event according to the energy released by the seismic slip in the fault plane (Kanamori and Abe 1979). The first step is to quantify the size of the seismic event after simulation for the ruptured surface of the fault zone. This attribute has been described as the seismic moment, $\mathrm{M}_{\mathrm{o}}$, defined by Kanamori and Brodsky (2001) as:

$\mathrm{M}_{\mathrm{o}}=\mu \mathrm{Ad}$

From Aki (1967), this expression can also be rewritten as:

$\mathrm{M}_{\mathrm{o}}=\mu \mathrm{LWD}_{\mathrm{c}}$

Here $\mathrm{M}_{\mathrm{o}}$ is the seismic moment $(\mathrm{Nm}), \mu$ is the shear modulus $(\mathrm{Pa}), \mathrm{A}$ is the rupture area $\left(\mathrm{m}^{2}\right), \mathrm{D}_{\mathrm{c}}$ is the mean slip $(\mathrm{m}), \mathrm{L}$ is the fault length $(\mathrm{m})$, and $\mathrm{W}$ is the fault rupture width $(\mathrm{m})$.

Estimating the moment magnitude $(\mathrm{M})$ of the seismic event involves the adoption of an equation which relates seismic moment, as given by Kanamori and Anderson (1975) thus:

$\mathrm{M}=\left(\frac{\log _{10} \mathrm{M}_{\mathrm{o}}}{1.5}\right)-6.1$

This $\mathrm{M}-\mathrm{M}_{\mathrm{o}}$ relationship can also be expressed (Kanamori and Abe 1979; Purcaru and Berckhemer 1982) as:

$M=(2 / 3)(\log 10 M o-9.1)$

\section{Model analysis}

The simulation for this study involved the use of the coupled hydro-mechanical simulator TOUGHREACT-FLAC3D developed by Taron et al. (2009), which links the TOUGHREACT multiphase flow with the FLAC3D geomechanical simulator (Itasca 2009). The elastoplastic behaviour of the fault in FLAC3D which occurs as a ubiquitous fractured media impressively represent an anisotropic mechanical behaviour. A coupled hydromechanical fault model can be developed within the framework of TOUGH-FLAC by utilizing existing capabilities within TOUGH2 and FLAC3D codes, and by developing specially designed coupling modules for faults. The fault model in TOUGH-FLAC could be discretized in terms of the mechanical behaviour of faults and fault zones represented in FLAC3D by either special zero-thickness mechanical interfaces (Fig. 2a), by an equivalent continuum representation using solid elements (Fig. 2b), or by a combination of solid elements and ubiquitous-joints oriented as weak planes (Fig. 2c). 
(a)

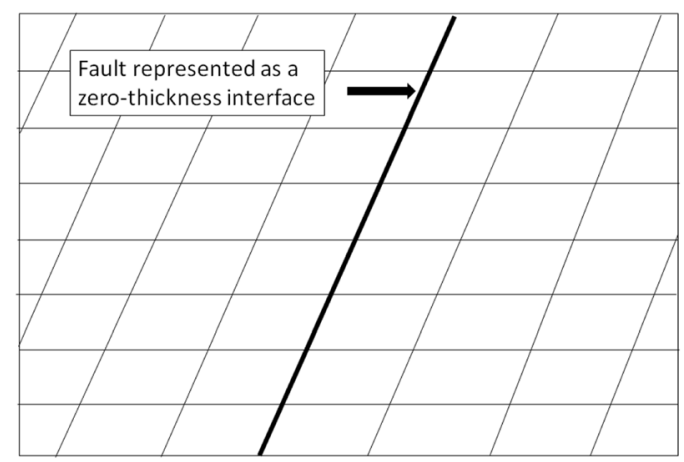

(b)

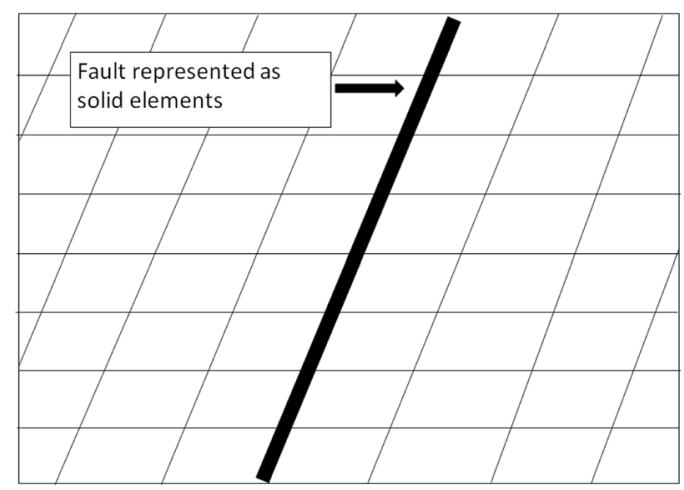

(c)

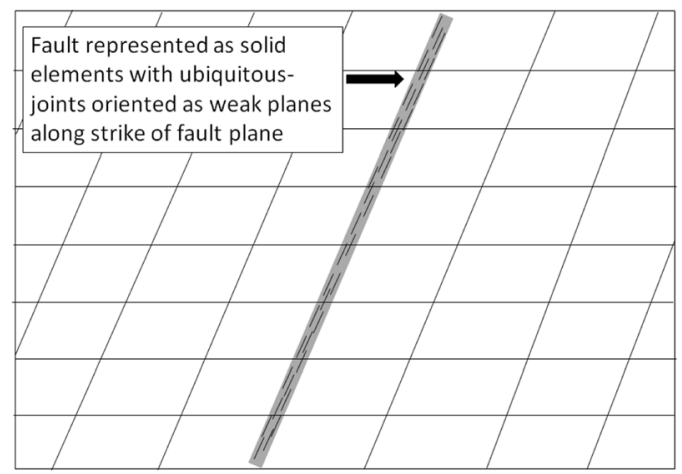

Fig. 2 Possible approaches for modeling of hydromechanical behaviour of a fault in TOUGH-FLAC where the fault is represented as a zero-thickness interface, $\mathbf{b}$ solid elements, and c solid elements with ubiquitous-joints oriented as weak planes along strike of fault plane (Cappa and Rutqvist 2011)

One merit of using solid elements as ubiquitous fractured media is the ability to model faults to account for parallel and cross fault heterogeneity. The mechanical behaviour of the fault as a ubiquitous fractured media accounts for the presence of an orientation of weakness (weak plane) in MohrCoulomb model (Cappa and Rutqvist 2011). The Mohr-Coulomb envelope has a tension cut off which serves as the criterion for failure on the fault weak planes (Hacker 1997). Using this procedure, it is possible to model the plastic flow behaviour for both the weak planes and rock matrix in the vicinity of the fault zone.

The fault is designed to contain a low permeability fault core which is flanked by slightly higher permeability damage zones. The elastoplastic constitutive model available in the FLAC3D was adopted in the study. The matrix was assigned Mohr-Coulomb model, while the constitutive model for the major fault was defined as strain-hardening/softening ubiquitous (subi) joint model. This choice is adequate to model the planes of weakness introduced by the fracture zones. The fault is set to be critically stressed, dipping towards the direction of the maximum principal stress (Fig. 3a). The fault architecture is designed with finer mesh than the other part of the reservoir. That is, the mesh size in fault and the matrix to the left and right of the fault zone contains uniform and smaller sizes than those in the other upper and lower regions of the matrix (Fig. 3b-d) to ensure accurate and efficient simulation of the zone of interest. The model was constructed using structured block grids in FLAC.

Table 1 shows the assumed material properties for the fault zone and host rock, derived from laboratory measurements and previously published data from the study area (Eyinla and Oladunjoye 2019; Chukwu 2017; Nwozor et al. 2017; Emudianughe and Ogagarue 2018; Ichenwo and Olatunji 2018; Ogunsakin et al. 2019; Eyinla et al. 2020, 2021). The constitutive mechanical properties for the model were derived from the work of Gan and Lei (2020). The study presents a simple reservoir model geometry with spatial dimension of $600 \mathrm{~m} \times 15 \mathrm{~m} \times 600 \mathrm{~m}(\mathrm{x}, \mathrm{y}$, $\mathrm{z}$ ), including a single hydraulically induced normal fault integrated in the model at interval 150 to $450 \mathrm{~m}$ (z-direction). For each model, three distinct fault orientations were examined, dipping at $\mathrm{NE} 45^{\circ}, \mathrm{NE}$ $60^{\circ}$ and NW $20^{\circ}$ denoted as angle $110^{\circ}$ (Fig. 3b-d). The fault is represented as solid elements with ubiquitous joints existing as weak planes with specific orientations with respect to the strike of the fault plane. Figure $3 \mathrm{a}$ is a schematic representation of $45^{\circ}$ fault angle, showing the assumed associated joints and their orientations. In this study, the specific joint direction assigned to each fault orientation are $145^{\circ}, 135^{\circ}, 70^{\circ}$, $50^{\circ}$ and $30^{\circ}$ (Table 2). 
(a)

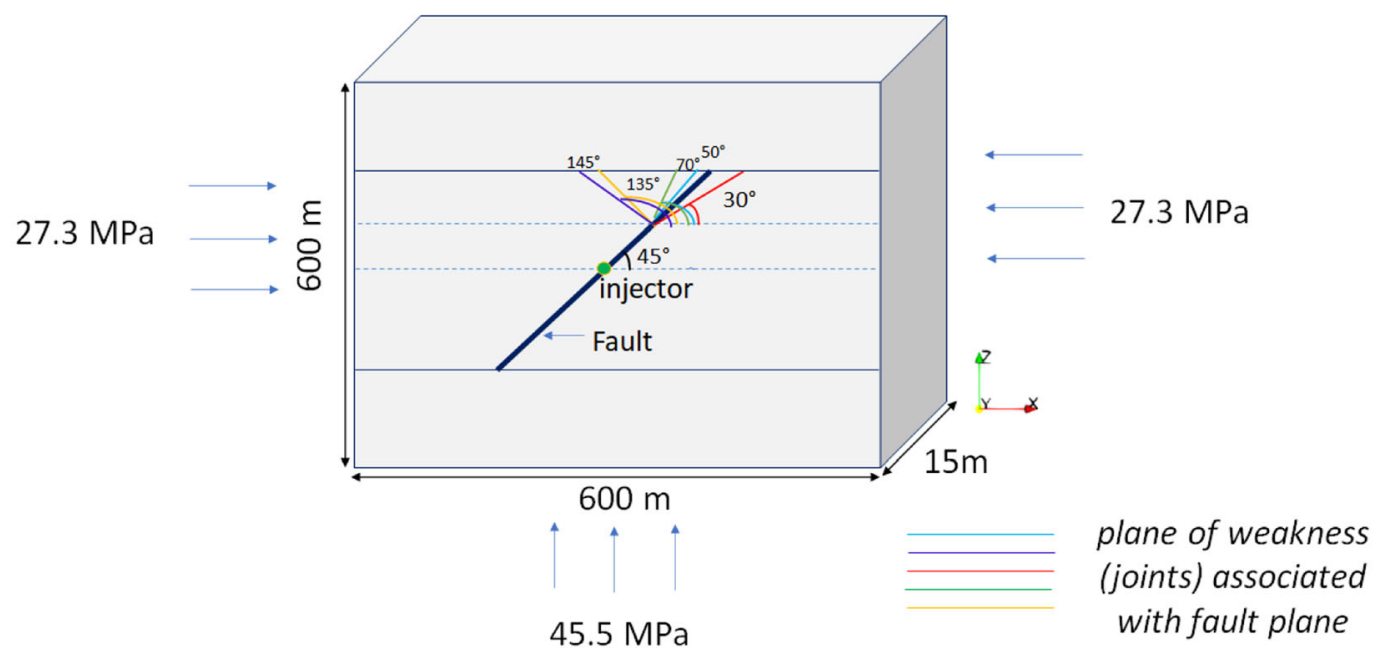

(b) $45^{\circ}$

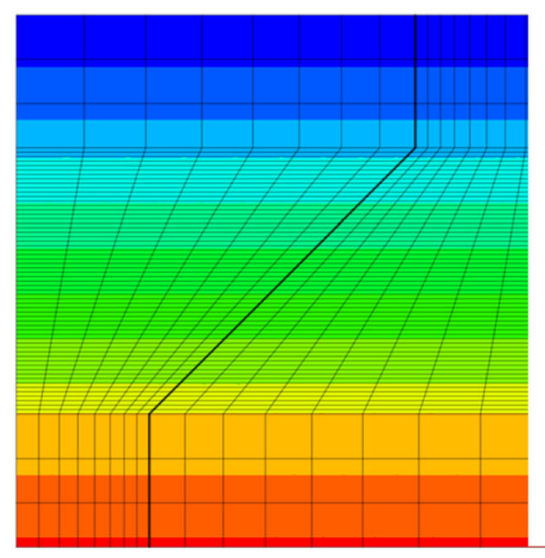

(c) $60^{\circ}$

(d) $110^{\circ}$

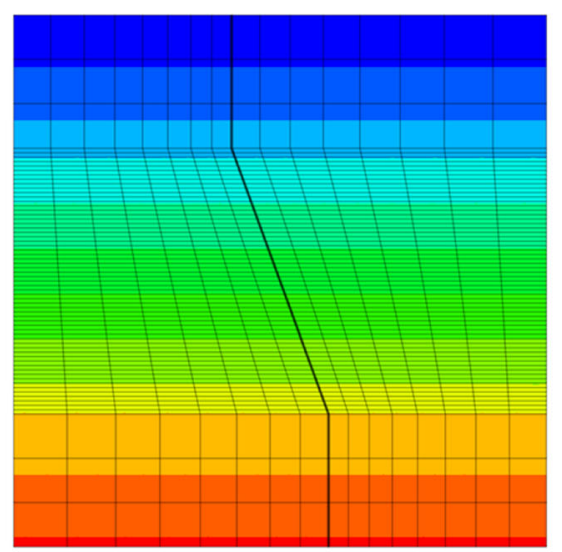

45.5 MPa

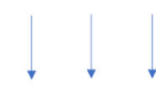


4 Fig. 3 a A schematic representation of $45^{\circ}$ fault model and orientation of associated joints b-d Model geometry for the three fault orientations at initial condition e Slip monitoring points on the fault plane for angle $45^{\circ}$

Table 2 Description of simulation scenarios considered in this study for various fault/joint configurations

\begin{tabular}{|c|c|c|c|}
\hline Scenarios & & Fault angle $\left({ }^{\circ}\right)$ & Joint orientation $\left({ }^{\circ}\right)$ \\
\hline \multirow[t]{3}{*}{1} & \multirow[t]{3}{*}{ CASE A } & 45 & 135 \\
\hline & & 60 & 135 \\
\hline & & 110 & 135 \\
\hline \multirow[t]{15}{*}{2} & \multirow[t]{5}{*}{ CASE B } & 45 & 30 \\
\hline & & 45 & 50 \\
\hline & & 45 & 70 \\
\hline & & 45 & 135 \\
\hline & & 45 & 145 \\
\hline & \multirow[t]{5}{*}{ CASE C } & 60 & 30 \\
\hline & & 60 & 50 \\
\hline & & 60 & 70 \\
\hline & & 60 & 135 \\
\hline & & 60 & 145 \\
\hline & \multirow[t]{5}{*}{ CASE D } & 110 & 30 \\
\hline & & 110 & 50 \\
\hline & & 110 & 70 \\
\hline & & 110 & 135 \\
\hline & & 110 & 145 \\
\hline
\end{tabular}

The model geometry constructed consists of 1320 elements: 1080 elements for the matrix, and 240 elements for the fault zone. These zones were populated with material properties in Table 1. This include hydraulic properties (e.g., porosity, permeability), elastic moduli (e.g., shear modulus, bulk modulus), material strength properties (e.g., tensile strength, friction angle, cohesion), amongst others. The elastoplastic constitutive model available in the FLAC3D was adopted in the study. The matrix was assigned Mohr-Coulomb model, while the constitutive model for the major fault was defined as strainhardening/softening ubiquitous (subi) joint model. This choice is adequate to model the planes of weakness introduced by the fracture zones. The fault architecture is designed with finer mesh than the other part of the reservoir. That is, the mesh size in fault and the matrix to the left and right of the fault zone contains uniform and smaller sizes than those in the other upper and lower regions of the matrix (Fig. 3bd) to ensure accurate and efficient simulation of the zone of interest. The model was constructed using structured block grids in FLAC.

It is expected that the fault core would serve as a barrier preventing fluid from penetrating across it, whereas the damage zones create permeable channels through which fluids are transmitted in parallel direction to the strike of the fault. Model boundaries are set at no flow boundaries, and the y-direction is set at roller condition with no normal displacement as constant stresses are applied (Gan and Lei 2020). The initial permeability of the fault core and damage zone are sets at $10^{-15} \mathrm{~m}^{2}$ and $10^{-14} \mathrm{~m}^{2}$ respectively, while the initial matrix permeability is set at $10^{-16} \mathrm{~m}^{2}$. An interesting component of this model is the ability of the fault permeability to evolve through time. Therefore, at the onset of slip, it is expected that the fault zone permeability would change, and there would also be a drastic reduction in the shear stress.

The friction angle of the fault joint is $28^{\circ}$ while the dilation angle is $5^{\circ}$. The injection well is centrally located along the fault mid-point and extends laterally towards the $\mathrm{y}$ axis $(15 \mathrm{~m})$, with a constant injection rate at $0.3 \mathrm{~kg} / \mathrm{s}$. The injection condition for this study is isothermal. The minimum principal stress acting on $\mathrm{x}$-direction was 27.3 $\mathrm{MPa}$ and the maximum principal stress was set at $45.5 \mathrm{MPa}$ (z-direction), they are illustrated in Fig. 3a. The permeability evolution model in FLAC3D adopted in this work has been verified in earlier studies by White et al. (2016). The behaviour of the model promotes permeability enhancement at the onset of fault slip as a result of the dilation angle of the fault.

\section{Simulation scenarios}

In the first scenario (Scenario A), there are three basic fault configurations $\left(45^{\circ}, 60^{\circ}\right.$ and $\left.110^{\circ}\right)$ with the same direction of joint which was assumed to be $135^{\circ}$ as shown in Table 2. Here we examined the sensitivity of each of the fault angles to hydromechanical processes induced by injecting fluids at a constant flow rate of $0.3 \mathrm{~kg} / \mathrm{s}$. We then further explored the effects of changing joint directions on the HM response of the three fault angles under the 5 chosen joint directions $\left(30^{\circ}, 50^{\circ}, 70^{\circ}, 135^{\circ}\right.$ and $\left.145^{\circ}\right)$ with the same injection 
rate at $0.3 \mathrm{~kg} / \mathrm{s}$. This investigation is to fully examine and certify the effect of each joint direction on the hydromechanical behaviour of the individual fault orientations. This is Scenario B, and the variations in fault/joint orientations was examined for permeability evolution as well as the magnitude of injectioninduced seismicity under the same matrix-fault properties and injection conditions. For the slip displacement measurement, points along the fault surface were recorded from A to G. Point A being the top of the fault and point $G$ is the base (Fig. 3e).

\section{Results and discussion}

An investigation into the effects of the frictional property and compaction dominating behaviour of the fault in this study has shown that HM interactions in the fault zone change with different fault angles. The results of the three fault angles $45^{\circ}, 60^{\circ}$ and $110^{\circ}$ for Scenario A (as shown in Table 2) revealed that angle $60^{\circ}$ has the highest permeability enhancement (Fig. 4). The timing of fault failure with changing fault angle is earliest in $45^{\circ}$ and most delayed in $110^{\circ}$ (Fig. 4a-e). Effective stress and shear stress magnitudes are greater at lower fault orientations as $45^{\circ}>60^{\circ}>110^{\circ}$ (Fig. 4d-e), and stress drop was highest at fault angle of $45^{\circ}$. However, the simulation result after changing the joint direction for each fault orientation showed how the joint greatly influence the fault stability and how the impact on permeability evolution for each model was revealed (Figs. 5, 6, 7). Also, the variation in shear failure tendency and eventual slip timing is different, as the slip potential is highly dependent on the joint direction with respect to the existing fault plane. This implies that with a change in the joint direction, there is an increasing possibility to have a different levels of fault criticality to failure. Additionally, Fig. 8 shows the correlation of each fault/joint model as shear slip is initiated when the shear strength limit (coefficient of friction, $\mu_{\mathrm{s}}=0.53$ ) is exceeded, and the principal effective stress ratio $\left(\sigma_{1}{ }^{\prime} / \sigma_{3}{ }^{\prime}\right)$ is greater than the effective stress limiting ratio $(\mathrm{q}=2.76)$. A slip will probably not occur even when the assumption about fault angle relationship with the direction of maximum stress is fulfilled if the angle between the joint and the principal stress is very large, just as is the case of $145^{\circ}$ and $30^{\circ}$ joint orientations, the fault tends to be relatively stable. The slip profile for the three fault angles under various joint configurations illustrate the magnitude of slip events much better in Figs. 9, 10, 11 and 12. The slip curves are dissimilar for each fault/joint model and the magnitude of fault displacement depends on the joint direction in relation to the fault plane and the direction of maximum principal stress.

\subsection{Effect of fault orientation}

Variation in the orientation of the fault dip created significant influence on the loading response, permeability evolution (Fig. 4a) and the slip tendency of the fault. It was observed that increasing the dip angle of the fault delays the slip timing (Fig. 4b), however, the three orientation angles displayed tendency of producing fracture slip under same hydromechanical properties and injection conditions adopted for the simulation. The onset of slip timing increases as the fault angle decreases. In this way, fault configuration with angle $45^{\circ}$ resulted in an earlier onset of slip after 15.7 days of injection, whereas slip occurred only after 16.7 days of injection in the case of $60^{\circ}$, and 19 days for fault angle $110^{\circ}$. This implies that the slip tendency of a pre-existing fault is controlled not only by the strength of fault (Eshiet and Sheng 2017; Eyinla et al. 2020), but also by the orientation of the fault.

Also, the magnitude of permeability enhancement after the onset of slip is significantly influenced by the fault orientations, as fault permeability was enhanced by one order of magnitude in angle $110^{\circ}$ (from $10^{-15}$ to $10^{-14}$ ), two orders of magnitude in the case of angle $45^{\circ}$ (from $10^{-15}$ to $10^{-13}$ ), and over four orders of magnitude in angle $60^{\circ}$ (from $10^{-15}$ to $10^{-10}$ ). From the work of Akande et al. (2021) that involved the same permeability evolution model, $60^{\circ}$ fault dip angle yielded the most interesting result for their study after comparing results from other fault angles. This is obviously the same with our study, where fault dip angle $60^{\circ}$ resulted in the highest permeability when compared with the other two fault angles.

The tendency of permeability enhancement as injection progresses arguably results from fault opening during sliding, mostly reflecting the roughness of the fracture walls and the effect of the associated microcrack dilatation occurring during the early stages of the fault failure (Guglielmi et al. 2015). However, the peak behaviour of each fault angle is well 

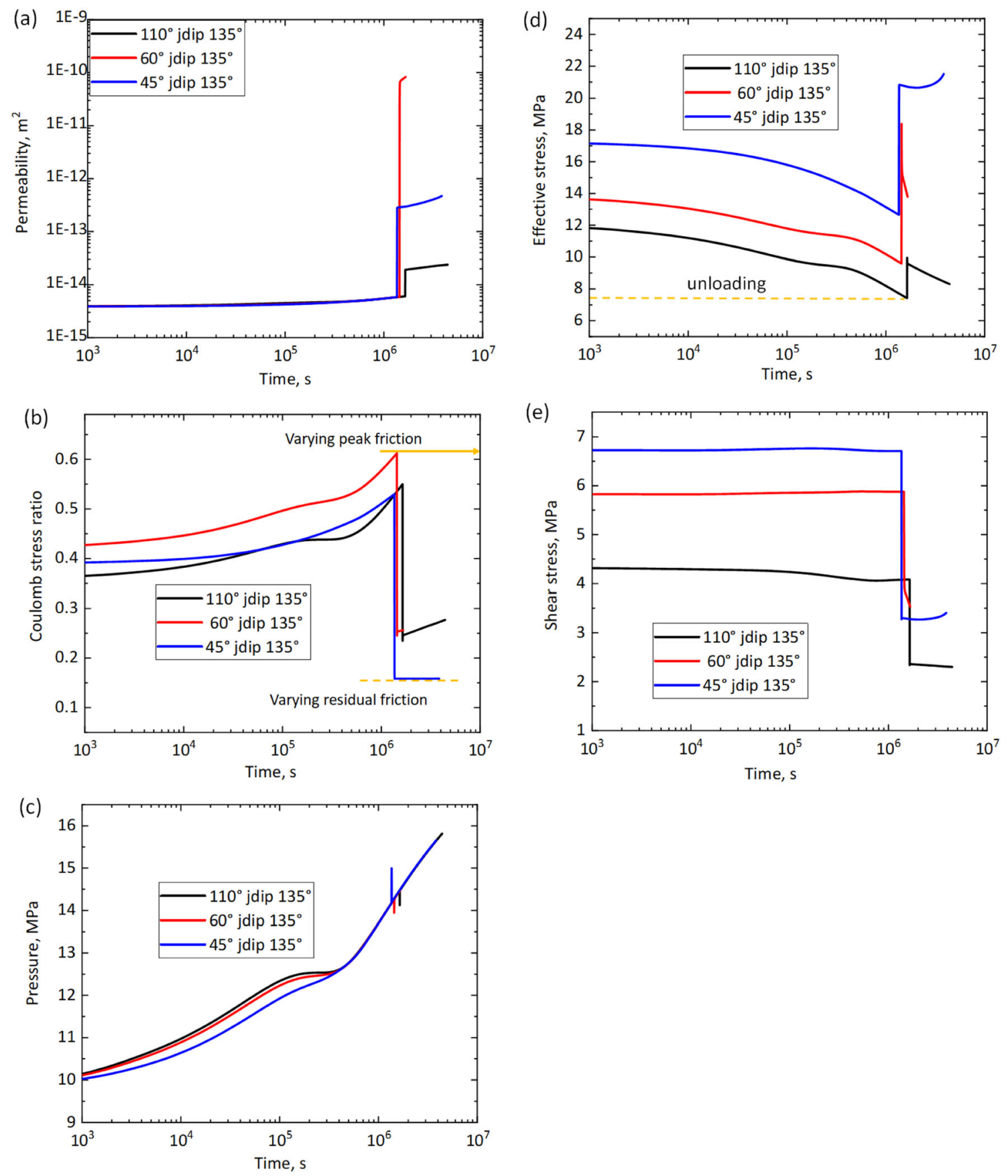

Fig. 4 a Evolution of fault permeability near the injection point at varying fracture orientation angle $110^{\circ}, 45^{\circ}$ and $60^{\circ}$ with same joint dip $135^{\circ}, \mathbf{b}$ evolution of Coulomb stress ratio at the

represented on the coulomb stress plot in Fig. 4b. The plot illustrates variation in frictional resistance of the fault as the orientation changes, despite the controlling effect of the peak friction angle and the residual

monitoring point, $\mathbf{c}$ evolution of pore pressure at the monitoring interval, $\mathbf{d}$ evolution of effective normal stress, e evolution of Shear stress at the same point

friction angle (Gan and Lei 2020). Previous reports by Cappa et al. (2018) and Gan and Lei (2020) showed how faults respond in terms of permeability enhancement when fault reactivation occurs. Seemingly, the 

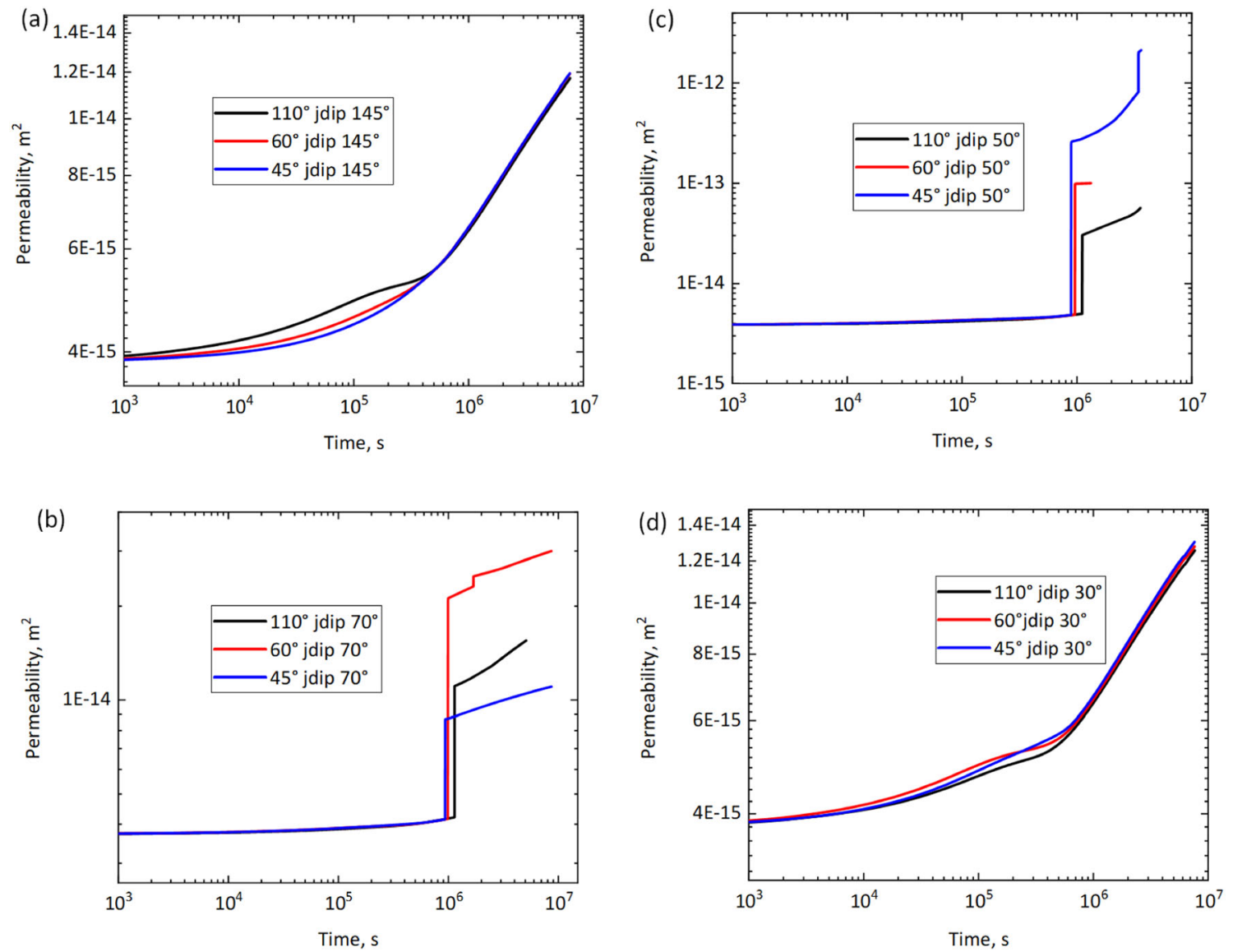

Fig. 5 Evolution of fault permeability of the three fault angles at various joint orientations a joint dip $145^{\circ}$ with no shear slip $\mathbf{b}$ joint dip $70^{\circ}$ with fault slip c joint dip $50^{\circ}$ with shear slip d joint dip $30^{\circ}$ with no shear slip

evolution of fault hydraulic features enables a clear behaviour of slip growth during fluid injection. Continuous permeability elevation after shear slip is evident in all the fault angles, with continuous pore pressure build-up. A steadily rising pore pressure is the usual poroelastic response of faulted reservoir to fluid injection, regardless of the injection fluid properties (Altmann et al. 2010; Schoenball et al. 2010; Vilarrasa et al. 2013; Kim and Hosseini 2014). Similarly, our results showed a continuous pressure build-up along the fault plane, meanwhile, the variation in this hydraulic response is a function of the aperture and the fault initial stability. This stability is dependent on the fault dip angle, which determines the angle between the fault plane and the direction of principal stress orientation (Streit and Hills 2004). There is a drop in pressure at the point of slip observed for fault angles $110^{\circ}$ and $60^{\circ}$ due to the significant void space creation through shear dilation. Conversely, there is a sudden rise in pressure just before the onset of shear failure for the case of angle $45^{\circ}$. It might be caused by the compaction effect of the pressure build-up in undrain conditions, with the increasing normal stress (Fig. 4d).

Clearly, there is an intricate interaction between fluid pressure, fault permeability and the corresponding deformation (Cappa et al. 2018). The result for the three fault angles showed that the fault permeability evolution is also pressure dependent, considering the increasing pressure observed as permeability enhancement evolves, and the corresponding sudden pressure excitation/relaxation as permeability changes with fault slip. This observation is similar to earlier reports by Barree et al. (2009), Cho et al. (2013), Wang and Sharma (2019), and Gan and Lei (2020). However, there is a higher stress sensitivity for low permeability 

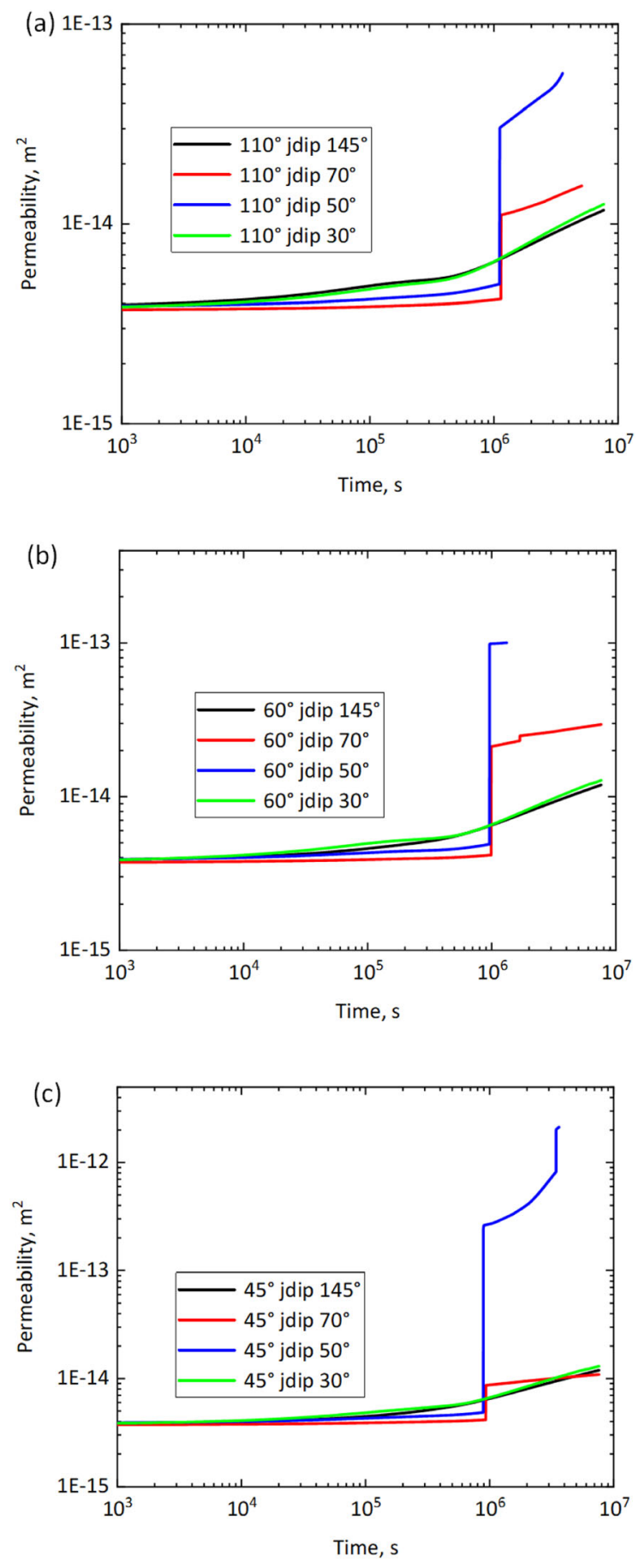

Fig. 6 Evolution of fault permeability with fault orientation a $110^{\circ}$ at various joint $\operatorname{dip} \mathbf{b} 60^{\circ}$ at various joint $\operatorname{dip} \mathbf{c} 45^{\circ}$ at various joint dip

fractured reservoirs, which obviously diminishes when the effective stress rises above certain level
(Archer 2008). This study observes a steady drop in stress as simulation commences (Fig. 4d), yielding a gradual permeability rise before slip (Fig. 4a).

Notably, when the fault plane reached a critical stress state, the unloading process was accompanied by a released strain energy. The fault angle with more shear stress produces earlier onset of slip, larger shear drops and larger slip zone, and this finding is consistent with reports in earlier studies by Rutqvist et al. (2015) and Guglielmi et al. (2015). This revealed why fault angle $45^{\circ}$ which results in a larger shear accumulation among the three fault orientations considered in this study also produced the earliest onset of slip, the largest shear drop, and the largest slip area. Although the slip distance in fault angle $60^{\circ}$ is highest among the three cases (Fig. 9a), the overall slip area in angle $45^{\circ}$ is the largest with 5 slip points (Fig. 9b), and this is a direct reflection of the magnitude of shear stress drop (Fig. 4e). This means that a fault with higher background stress would produce larger slip growth simultaneously (Cappa et al. 2018). The stress reduction during unloading is mostly due to interparticle force decrease and continuous particle contact breakage. Nonetheless, the effect of changing frictional property and compaction dominating behaviour of the fault as orientation changes has greatly influenced the variation in shear slip timing.

Furthermore, in response to loading, while permeability is significantly enhanced when stress is elevated, effective stress evolution affects both the timing of the slip and the size of the corresponding slip area. Meanwhile, stress anisotropy is increasingly developed as the angle between the fault plane and the maximum principal stress increases. Fault angle $45^{\circ}$ being the highest in this case developed the highest magnitude of effective stress, followed by angle $60^{\circ}$. However, regardless of the effective stress and shear stress elevation and magnitudes, the resulting final permeability enhancement after shear failure is highly dependent on the shear strain and shear dilation of the elasto-plastic model as reported by Rutqvist et al. (2013).

\subsection{Effect of joint orientation}

The previous section assumed $135^{\circ}$ as the joint dip angle for the three fault orientations, indicating that the results obtained did not consider the effect of the 

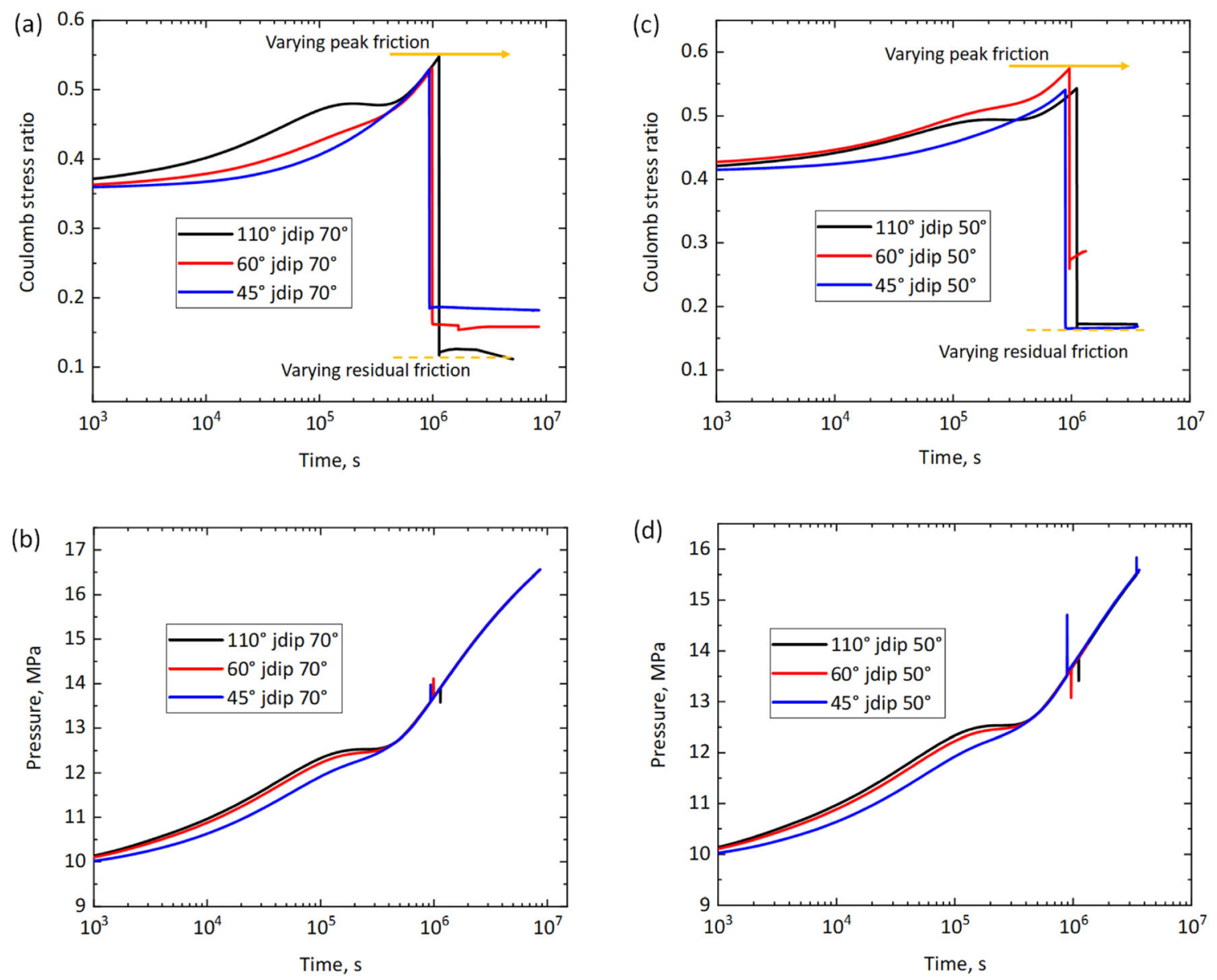

Fig. 7 a Evolution of Coulomb stress ratio at the centre of fault with the three fault angles and joint $\operatorname{dip} 70^{\circ} \mathbf{b}$ Evolution of pore pressure acting on transition near fault centre with the three fault angles and joint dip $70^{\circ} \mathbf{c}$ Evolution of Coulomb stress ratio at

joint dip on the permeability evolution. Figure 5a-d, however, show the effect of various joint dips on the fault permeability enhancement among the three fault orientations. The fault configurations are plotted together to discern the variation of fault permeability in the same joint direction. Although the relationship of the fault plane with respect to the maximum principal stress direction has been observed to determine fault stability, our results have showed that fault slip potential is also dependent on the joint direction with respect to the existing fault plane (Figs. 5, 6, 7). Literally, a slip will probably not occur when the earlier assumption about fault-maximum stress direction relationship $(12,14,39)$ is fulfilled. That is, if the angle between the joint plane and the maximum principal stress direction is large, as in the case of joint

the centre of fault with the three fault angles and joint dip $50^{\circ}$ d Evolution of pore pressure acting on transition near fault centre with the three fault angles and joint dip $50^{\circ}$

$\operatorname{dip} 145^{\circ}$ and $30^{\circ}$ in Fig. 5a and d. The effect of joint direction in these two cases promote very high fault compaction and increasing frictional resistance which influences the fault plane to resist shear deformation. This is because with the extremely high stability of the fault plane induced by the joint, fault slip tendency is negligible, thus, no amount of fluid pressurization is sufficient to overcome the frictional strength and the resistance to slip within the limit of our experiments. Overall, as the stability becomes more enhanced in the fault plane, fault slip tendency is lowered. A related observation was reported by Grasselli and Egger (2003) and Jacquey et al. (2015).

As this study has revealed, the most significant fault permeability enhancement is only observed when there is a shear slip. From result, the variation in slip 
tendency and permeability evolution is enhanced as the joint angle changes indicating that permeability enhancement is strongly affected by the joint orientation in the model, as it affects the stress state and slip potential. Here, joint direction of angle $50^{\circ}$ produced the highest permeability enhancement for the three fault angles (Fig. 5c), invariably, the highest slip distance in each fault/joint model.

This implies that with a changing joint direction, there is an increasing possibility to have a different levels of fault criticality to failure. In the case of fault angle $110^{\circ}$, all the associated joint dip angles generally produced low permeability enhancement compared to the other two faults angles. The enhancement after slip lies within two orders of magnitudes, even with intermediate joint dip $50^{\circ}$, yielding the most significant permeability increase for fault angle $110^{\circ}$ (Fig. 6a). However, in fault angle $45^{\circ}$, joint dip $50^{\circ}$ also produced the highest permeability enhancement, but it is quite more enhanced than it was in fault angle $110^{\circ}$, increasing from the order of $10^{-15} \mathrm{~m}^{2}$ to $10^{-12}$ $\mathrm{m}^{2}$. (Fig. 6c). This is higher than the enhancement observed in fault angle $45^{\circ}$ with joint dip $135^{\circ}$ (Fig. 4a), which increases from the order of $10^{-15}$ $\mathrm{m}^{2}$ to $10^{-13} \mathrm{~m}^{2}$, whereas $45^{\circ}$ joint dip $70^{\circ}$ only increases with less than an order of magnitude after slip (from $10^{-15} \mathrm{~m}^{2}$ to $10^{-14} \mathrm{~m}^{2}$ ). Nevertheless, fault angle $60^{\circ}$ with joint dip $135^{\circ}$ produced the highest permeability enhancement (Fig. 4a) when compared to the others under CASE C (Table 2, and Fig. 6b). This also vividly suggests an increasing slip distance during shear failure.

Evidently, as the joint direction changes, the mechanism of slip reactivation on preexisting faults when the Coulomb failure point is reached respond to the changing frictional resistance. The resultant effect
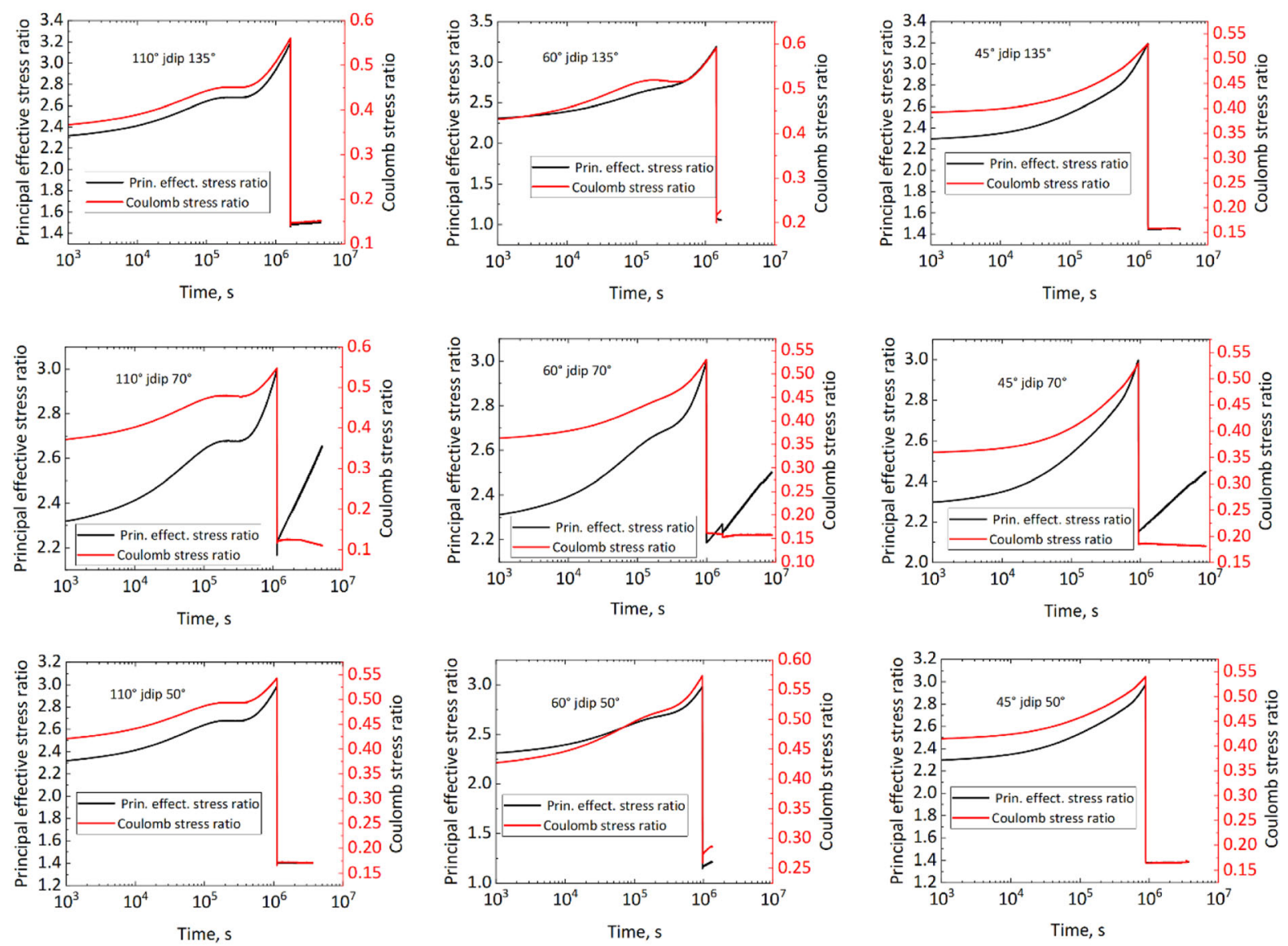

Fig. 8 Variation of frictional strength of fault with changing fault angle and joint orientation, showing how slip is initiated when shear limit $(0.53)$ is exceeded (Right hand side) and principal effective stress ratio is greater than effective stress limiting ratio (2.76) (Left hand side) 

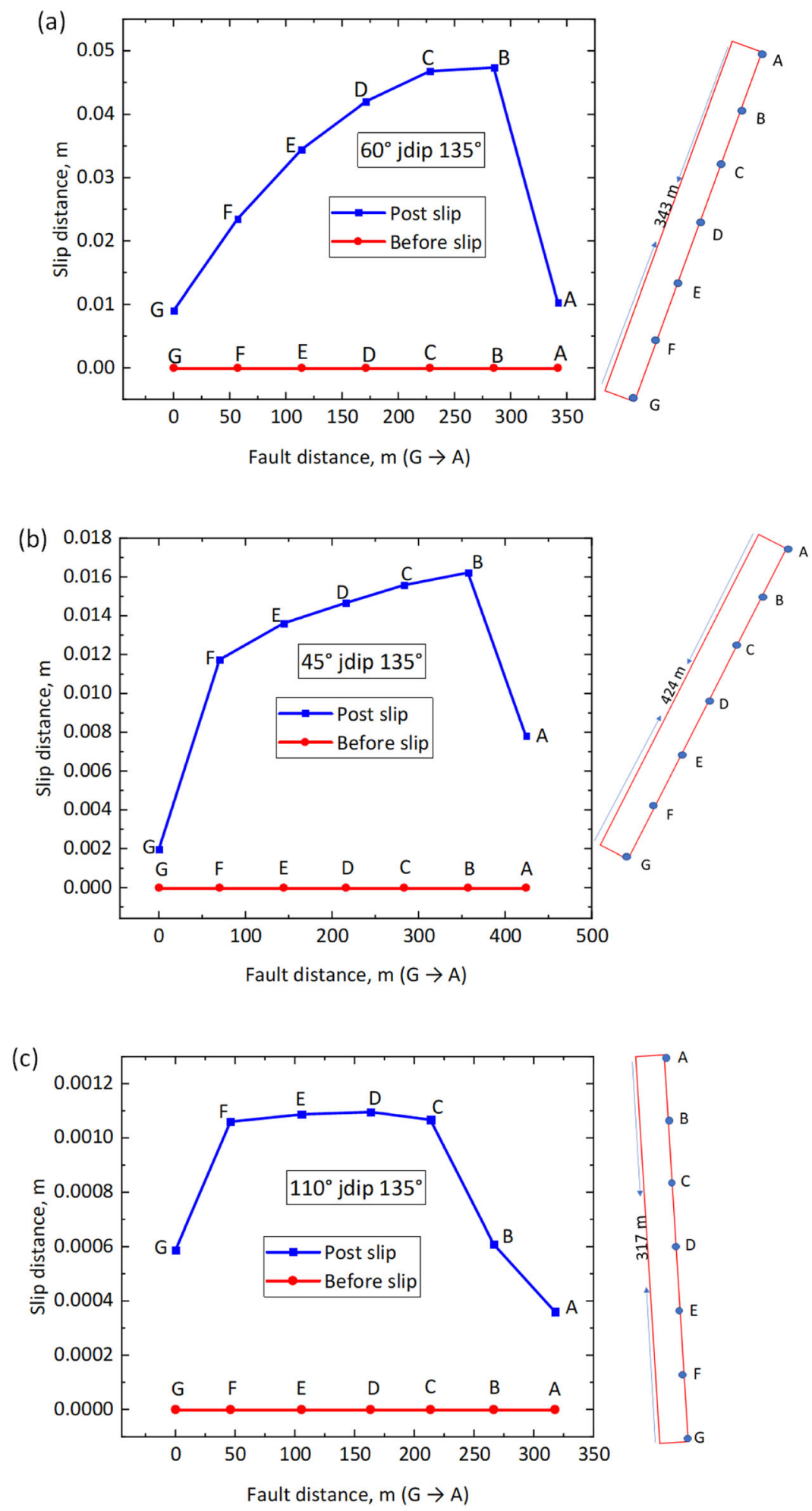

Fig. 9 Fault slip distance profile of the three fault orientations with joint dip $135^{\circ}$ in decreasing order of slip distance $\mathbf{a} 60^{\circ} \mathbf{b} 45^{\circ} \mathbf{c} 110^{\circ}$ 
Fig. 10 Fault slip distance profile of the three fault orientations with joint dip $70^{\circ}$ in decreasing order of slip distance a $60^{\circ}$ jdip $70^{\circ}$ b $45^{\circ}$ jdip $70^{\circ}$ c $110^{\circ}$ jdip $70^{\circ}$
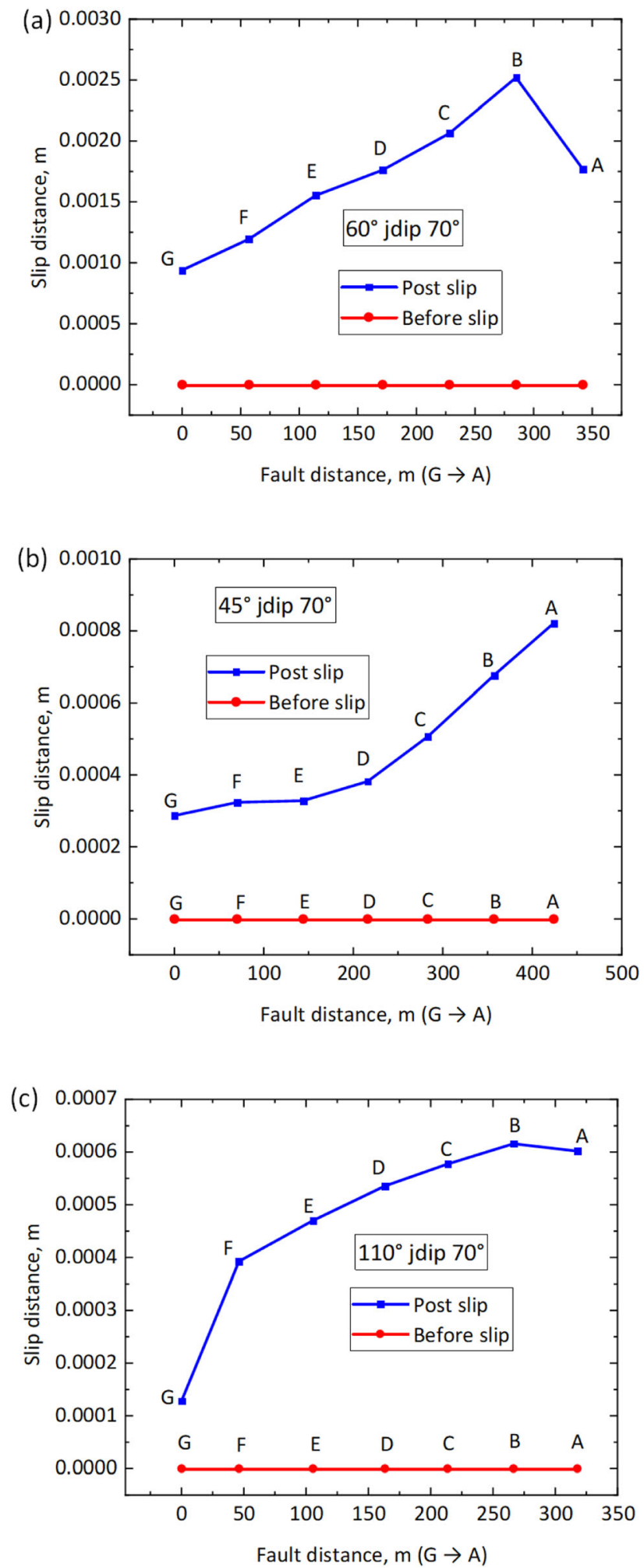

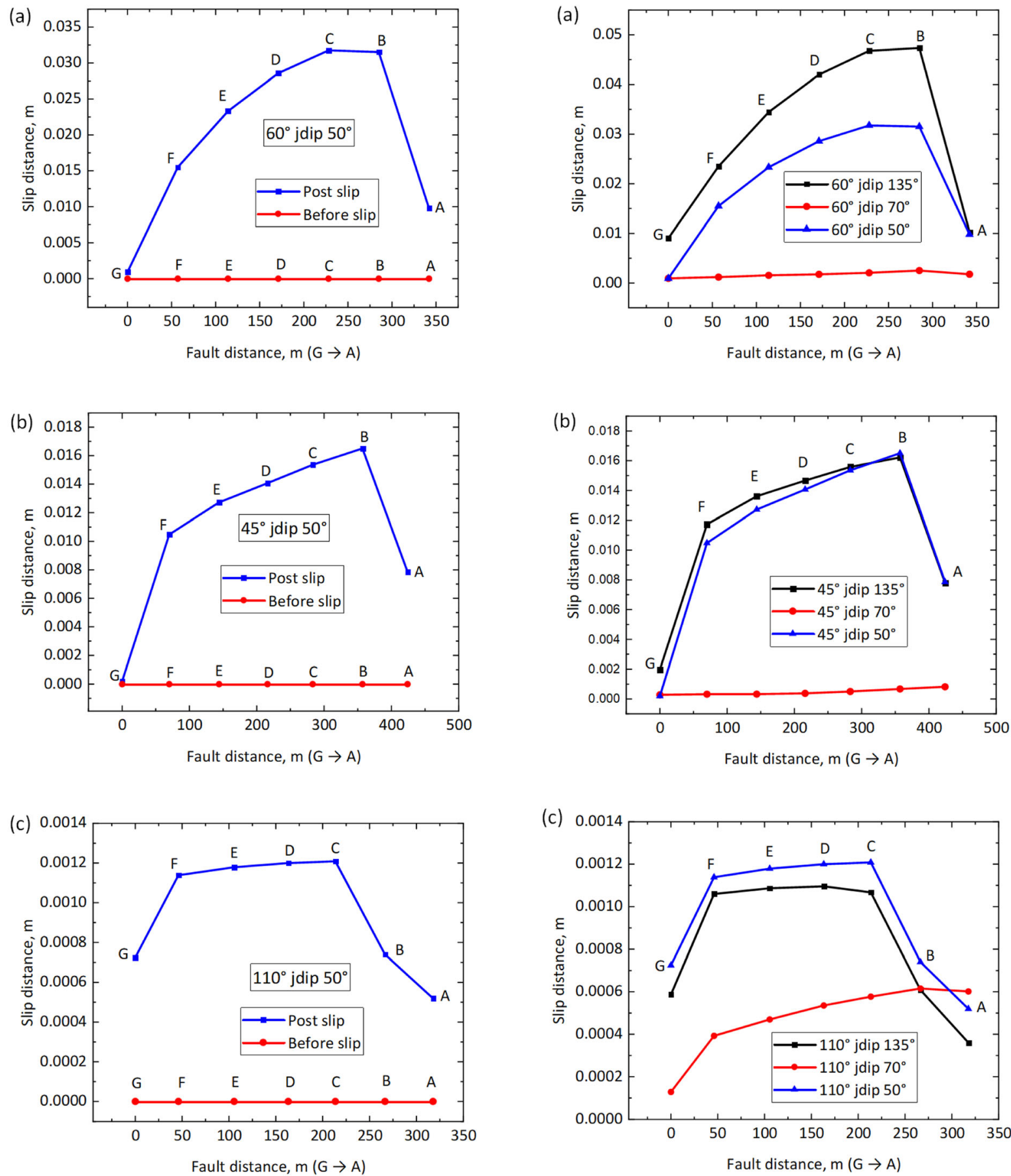

Fig. 11 Fault slip distance profile of the three fault orientations with joint dip $50^{\circ}$ in decreasing order of slip distance a $60^{\circ}$ jdip $50^{\circ} \mathbf{b} 45^{\circ}$ jdip $50^{\circ}$ c $110^{\circ}$ jdip $50^{\circ}$

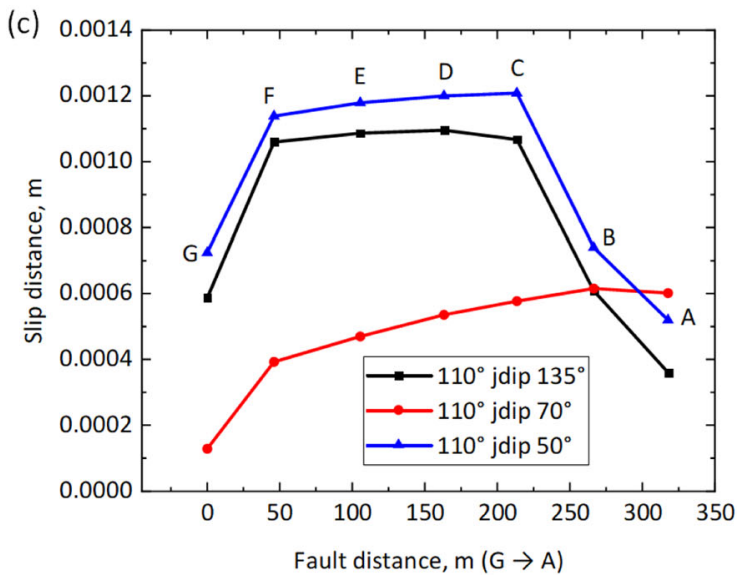

Fig. 12 Fault slip variation of fault angle a $60^{\circ}$ with different joint dip orientations. $\mathbf{b} 45^{\circ}$ with different joint dip orientations c $110^{\circ}$ with different joint dip orientations 
of this is the observed variation in Coulomb failure point, where the variation in critical peak friction value highlights the effects of the joint dips (Fig. 7a, c). However, the steep pore pressure surge noticed in Fig. $8 \mathrm{~b}$ and $\mathrm{d}$ reflects the timing when the shear slip occurs. Interestingly, we observed a less pronounced slip event in the case of joint dip $70^{\circ}$ as shown in Figs. 10c and 12. The joint plane in this case is closer to the vertical (maximum stress direction). However, intermediate joint orientation $\left(50^{\circ}\right.$ and $\left.135^{\circ}\right)$ causes friction weakening which promotes lowering of fault strength, consequently, influencing accelerated slip (Figs. 9, 11, 12). In this study, it is observed that the rate at which fault reaches its peak strength is much higher with an intermediate joint dip and fault orientation (Fig. 8).

Nevertheless, since earlier studies using the same model and simulation parameters have underscore the response of the fault under different injection position and flow rates (Eyinla et al. 2020), it will be worthwhile to investigate thermal influence on the behaviour of each fault/joint model in terms of fault reactivation potential and seismicity magnitude. Moreover, for a complex fracture system, the combined effect of the different orientations might produce a significant contribution to the overall result.

\subsection{Slip distance analysis}

To further investigate the extent and magnitude of shear failure as fluid pressure induces frictional behaviour, this study explores the slip distance measurement to illustrate the impact of fault and joint orientations on induced seismicity during fluid injection. Notably, during injection, critical high fluid pressure causes fault opening and seismic slip when the shear strength of the fault is exceeded. However, the overall effect of the injection process is mostly felt around the injector location (Cappa et al. 2018), and the induced seismicity, which is created by the continuous fluid injection, is often activated indirectly at some distance away from the injector position via stress transfer mechanism associated with disseminating fault slip propagation (Guglielmi et al. 2015). This model showed that enhanced permeability favours the growth of aseismic slip even beyond the pressurized area. The seismic rupture propagates away from the injector to enhance permeability through shear dilation, although the weakening/reduction of fault strength is more pronounced at the pressurized zone than in the immediate vicinity. However, when monitoring near the injection point, where fluid pressure is most elevated, aseismic slip is predominantly driven by effective stress reduction.

The slip magnitude is also directly linked to the growth of permeability, the larger slip distance leads to the higher permeability enhancement in the scenario of $60^{\circ}$ dip angle. (Figs. 4, 9). In this case, the slip distance profile along the fault damage zone shows how the size of slip zone varies as the fault angle changes. Fault angle $60^{\circ}$ delivers the highest slip distance in the range $0.025-0.045 \mathrm{~m}$ in all the three joint dip orientation (Figs. 9-12). This is followed by fault angle $45^{\circ}$ with the highest slip distance being recorded in joint direction $50^{\circ}$ as $0.16 \mathrm{~m}$ (Fig. 11b). Generally, fault angle $110^{\circ}$ delivers the lowest slip distance, regardless of the associated joint orientation (Figs. 9c, 10c,11c, 12c). The slip magnitude in the case of fault angle $110^{\circ}$ is highest in joint dip $50^{\circ}$ with slip distance $0.012 \mathrm{~m}$ (Fig. 11c). This therefore implies that under same injection conditions, the most unstable among the three fault orientations is $60^{\circ}$, with the highest likelihood of a slip at most joint orientations (Figs. 9a, 10a, 11a, 12a).

There is a higher fault permeability yield when the fault dip angle has lower frictional resistance, thus, producing high slip distance. Thus, increased shear stress produces faster onset of slip, and this results in a larger slip area (Cappa et al. 2018), which was observed in the case of fault $45^{\circ}$ with highest shear stress (Fig. 4e) and producing the largest slip area (Figs. 9b, 11b, 12b). The influence of joint dip angle on slip distance and permeability evolution was also evident, as angles with intermediate joint dips are observed to induce high slip displacement (Figs. 9, 11, 12) than very high dip angles (Figs. 10, 12).

It was believed that mesoscale fractures and inter and intragranular cracks are developed within fractures with high slip displacement (Tanikawa et al. 2010). Apparently, this established why fault angle $60^{\circ}$ with joint dip $135^{\circ}$ produced the highest permeability enhancement at the end of injection, from initial order of $10^{-15} \mathrm{~m}^{2}$ to $10^{-10} \mathrm{~m}^{2}$ compared to the other two fault angles. Thus, permeability enhancement during fault injection varies by different orders of magnitude (generally from 1 to 5), depending on the fault/joint orientation. However, the induced seismicity on the fault plane for the various fault/joint 
orientations have moment magnitude, $\mathrm{M}$, ranging from 0 to 1.0 , indicating very low aseismic event. Here, seismicity is highest in fault angle $60^{\circ}$ jdip $135^{\circ}$ than the other two fault/joint models, which suggests that the moment magnitude is dependent on the fault initial stability being proportional to the associated joint direction. Thus, the amount of slip resulting from fault failure determines the magnitude of seismicity.

\section{Conclusions}

This paper explores how the frictional equilibrium of pre-existing fault is altered in a diversified range as stress redistribution in the vicinity of the fault changes. Distinctly, the mechanism driving unloading-induced fault instability have been presented with much emphasis on the frictional resistance of the fault due to changing orientation using the Mohr-Coulomb model. This study has presented an exclusive description of how different fault orientations and associated joint directions may interact with the stress distribution during direct injection into the fault zone for the purpose of enhancing the permeability. Fault reactivation and injection-induced seismicity, in terms of timing and slip displacement magnitude, have been found to depend on different fracture configurations. Evidently, fault reactivations occurred when the accumulated shear stress acting on the fault plane exceeds its shear resistance, and the effective stress in the fault zone must respond to loading before any fault failure can occur.

The following summary resulted from the fluid injection simulation study:

1. Lower fault angles generally favor early onset of fault slips $\left(45^{\circ}>60^{\circ}>110^{\circ}\right)$, but the absolute effect of fault configurations is further modulated by the directions of associated joints with respect to the fault plane and the direction of maximum principal stress $\left(\sigma_{1}\right)$. That is, both fault and associated joints' direction have a first-order control over permeability evolution and fault reactivation during fluid injection.

2. With increasing distance of the joint plane from $\sigma_{1}$, frictional strength of the joint increases, and the joint planes thus promote further fault compaction. For instance, joints with very low dip oriented at $030^{\circ}$ and very high dip oriented at $145^{\circ}$ result in the lowest and insignificant fault permeability enhancement during the stimulation in all fault scenarios. These two joint directions yielded no fault failure because the effect of their direction confer special frictional stability on the fault plane instead of inducing fault slip as in other joint directions examined $\left(50^{\circ}, 70^{\circ}\right.$, and $\left.135^{\circ}\right)$.

3. The slip timing and slip tendency change as the fault angle and joint orientation change. This result is also evident in the permeability evolution. However, joint direction of angle $50^{\circ}$ produced the earliest onset of slip in all fault angles. It also resulted in the highest permeability enhancement for the three fault angles, and invariably, the highest slip distance among all the simulation scenarios of fault/joint model.

4. Permeability enhancement during fault injection varies in order of magnitudes depending on the position of fault plane relative to joint orientation, and the incurred slip distances have positive contribution in enhancing the magnitude of joint aperture through shear dilation, thereby enhancing the permeability of fault after slip.

5. Both the effective stress and shear stresses have a steep rise when the fault approaches a critical state of failure, and the magnitude of this elevated stresses is highly sensitive to the orientation geometry of the fault and joint. Fault angle with higher effective stress during unloading is also consistent with developing higher shear stress, as seen in the case of angle $45^{\circ}$. Meanwhile, this similar order of effective stress and shear stress magnitude define the timing and onset of slip, where fault angle $45^{\circ}$ yielded the largest shear and effective stress magnitude and thus results in earliest onset of slip.

6. The seismicity resulting from fluid injection depends on the slip tendency and the slip magnitude which has a direct correlation with the fault initial stability in terms of the relationship with the associated joint. The fault angle which produced the highest shear enhanced permeability produced the largest aseismic event, and from our study, fault angle $60^{\circ}$ jdip $135^{\circ}$ produced the most enhanced permeability, up to $10^{-10} \mathrm{~m}^{2}$ and thus, the highest slip displacement and seismicity $(\mathrm{M}=1.0)$. 
The implications from this study would enable a more accurate injection well placement and guidance when exploiting faults and understanding their behaviours as conduits during recovering subsurface energy so that production can be maximized. There is a direct connection between permeability changes and effective stress changes in the fault zone, which is also proportional to the magnitude of accompanied seismic event and slip zone.

Acknowledgements The authors wish to acknowledge the African Union Commission for providing the financial support through Pan African University; and the University of Aberdeen for providing the facilities and enabling environment for this study.

\section{Declaration}

Conflict of interest The authors declare that there is no conflict of interest regarding the publication of this paper.

Open Access This article is licensed under a Creative Commons Attribution 4.0 International License, which permits use, sharing, adaptation, distribution and reproduction in any medium or format, as long as you give appropriate credit to the original author(s) and the source, provide a link to the Creative Commons licence, and indicate if changes were made. The images or other third party material in this article are included in the article's Creative Commons licence, unless indicated otherwise in a credit line to the material. If material is not included in the article's Creative Commons licence and your intended use is not permitted by statutory regulation or exceeds the permitted use, you will need to obtain permission directly from the copyright holder. To view a copy of this licence, visit http://creativecommons.org/licenses/by/4.0/.

\section{References}

Adachi J, Siebrits E, Peirce A, Desroches J (2007) Computer simulation of hydraulic fractures. Int J Rock Mech Min Sci 44(5):739-757

Akande WG, Gan Q, Cornwell DG, De Siena L (2021) Thermohydro-mechanical model and caprock deformation explain the onset of an on-going seismo-volcanic unrest. J Geophys Res Solid Earth. https://doi.org/10.1029/2020JB020449

Aki K (1967) Scaling law of seismic spectrum. J Geophys Res 72(4):1217-1231. https://doi.org/10.1029/JZ072i004p012 17

Altmann JB, Müller TM, Müller BI, Tingay MR, Heidbach O (2010) Poroelastic contribution to the reservoir stress path. Int J Rock Mech Min Sci 47:1104-1113

Archer RA (2008) Impact of stress sensitive permeability on production data analysis. In: Proceedings of the SPE unconventional reservoirs conference, Keystone, CO, USA, 10-12 Feb 2008. SPE-114166-MS
Asahina D, Pan P, Tsusaka K, Takeda M, Bolander JE (2018) Simulating hydraulic fracturing processes in laboratoryscale geologicalmedia using three-dimensional TOUGHRBSN. J Rock Mech Geotech Eng 10:1102-1111. https:// doi.org/10.1016/j.jrmge.2018.09.001

Athavale AS, Miskimins JL (2008) Laboratory hydraulic fracturing on small homogeneous and laminated blocks. In: 42nd US rock mechanics symposium, San Francisco June 29-July 2

Barree RD, Barree VL, Craig D (2009) Holistic fracture diagnostics: consistent interpretation of prefrac injection tests using multiple analysis methods. SPE Prod Oper 24(03):396-406. https://doi.org/10.2118/107877-PA

Biot M (1941) General theory of three-dimensional consolidation. J Appl Phys 12(2):155-164

Blair SC, Thorpe RK, Heuze FE, Shaffer RJ (1989) Laboratory observations of the effect of geologic discontinuities on hydrofracture propagation. In: Khair AW (ed) Rock mechanics as a guide for efficient utilization of natural resources. Balkema, Rotterdam

Brown SR (1987) Fluid flow through rock joints: the effect of surface roughness. J Geophys Res 92(B2):1337-1347

Byerlee J (1978) Friction of rocks. Pure Appl Geophys 116(4-5):615-626

Candela T, Brodsky EE, Marone C, Elsworth D (2014) Laboratory evidence for particle mobilization as a mechanism for permeability enhancement via dynamic stressing, earth planet. Sci Lett 392:279-291. https://doi.org/10.1016/j. epsl.2014.02.025

Cappa F, Rutqvist J (2011) Modeling of coupled deformation and permeability evolution during fault reactivation induced by deep underground injection of $\mathrm{CO}_{2}$. Int $\mathrm{J}$ Greenh Gas Control 5(2011):336-346. https://doi.org/10. 1016/j.ijggc.2010.08.005

Cappa F, Guglielmi Y, Nussbaum C, Birkholzer J (2018) On the relationship between fault permeability increases, induced stress perturbation, and the growth of aseismic slip during fluid injection. Geophys Res Lett. https://doi.org/10.1029/ 2018GL080233

Casas L, Miskimins JL, Black A, Green S (2006) Laboratory hydraulic fracturing test on a rock with artificial discontinuities. In: SPE annual technical conference and exhibition, San Antonio, Texas, USA, 24-27 Sept

Cho Y, Apaydin OG, Ozkan E (2013) Pressure-dependent natural-fracture permeability in shale and its effect on shalegas well production. SPE Reserv Eval Eng 16:216-228

Chukwu GU (2017) Evaluation of geopressure regime in an Onshore Niger Delta Field of Nigeria. Biodivers Int J. https://doi.org/10.15406/bij.2017.01.00026

Chuprakov DA, Akulich AV, Siebrits E, Thiercelin M (2010) Hydraulic fracture propagation in a naturally fractured reservoir. In: SPE oil and gas India conference and exhibition in Mumbai, India, 20-22 Jan

Davies R, Foulger G, Bindley A, Styles P (2013) Induced seismicity and hydraulic fracturing for the recovery of hydrocarbons. Mar Pet Geol 45:171-185

Elkhoury JE, Niemeijer A, Brodsky EE, Marone C (2011) Laboratory observations of permeability enhancement by fluid pressure oscillation of in-situ fractured rock. J Geophys Res 116:B02311. https://doi.org/10.1029/ 2010JB007759 
Emudianughe JE, Ogagarue DO (2018) Investigating the subsurface pressure regime of ada-field in Onshore Niger Delta Basin Nigeria. J Geol Geophys. https://doi.org/10. 4172/2381-8719.1000452

Eshiet KI, Sheng Y (2017) The role of rock joint frictional strength in the containment of fracture propagation. Acta Geotech 12:897-920. https://doi.org/10.1007/s11440-0160512-2

Eyinla DS, Oladunjoye MA (2019) Empirical analysis for the characterization of geo-mechanical strength and pressure regime: implications on hydraulic fracturing stimulation. Petroleum. https://doi.org/10.1016/j.petlm.2018.05.002

Eyinla DS, Oladunjoye MA, Gan Q, Olayinka AI (2020) Fault reactivation potential and associated permeability evolution under changing injection conditions. Petroleum. https://doi.org/10.1016/j.petlm.2020.09.006

Eyinla DS, Oladunjoye MA, Olayinka AI, Bate BB (2021) Rock physics and geomechanical application in the interpretation of rock property trends for overpressure detection. J Pet Explor Prod Technol 11:75-95. https://doi.org/10. 1007/s13202-020-01039-4

Fairhurst C (2013) Fractures and fracturing: hydraulic fracturing in jointed rock. InTech, Rijeka. https://doi.org/10.5772/ 56366

Faoro I, Elsworth D, Marone C (2012) Permeability evolution during dynamic stressing of dual permeability media. J Geophys Res 117:B01310. https://doi.org/10.1029/ 2011JB008635

Feng J, Li L, Jin J, Dai J, Luo P (2018) An improved geomechanical model for the prediction of fracture generation and distribution in brittle reservoirs. PLOS ONE 13(11):e0205958. https://doi.org/10.1371/journal.pone. 0205958

Gan Q, Elsworth D (2014) Analysis of fluid injection-induced fault reactivation and seismic slip in geothermal reservoirs. J Geophys Res Solid Earth 119:3340-3353. https://doi.org/ 10.1002/2013JB010679

Gan Q, Elsworth D (2016a) Production optimization in fractured geothermal reservoirs by coupled discrete fracture network modeling. Geothermics 62:131-142. https://doi.org/10. 1016/j.geothermics.2016.04.009

Gan Q, Elsworth D (2016b) A continuum model for coupled stress and fluid flow in discrete fracture networks. Geomech Geophys Geo-Energy Geo-Resour 2(1):43-61. https://doi.org/10.1007/s40948-015-0020-0

Gan Q, Lei Q (2020) Induced fault reactivation by thermal perturbation in enhanced geothermal systems. Geothermic 86(101814):1-12. https://doi.org/10.1016/j.geothermics. 2020.101814

Ghosh S, Milad B, Prasun S, Ghosh SS (2018) Origin and characterization of joints in sedimentary rocks: a review. Pet Pet Chem Eng J 2(5):1-12

Grasselli G, Egger P (2003) Constitutive law for the shear strength of rock joints based on three-dimensional surface parameters. Int J Rock Mech Min Sci 40:25-40

Guglielmi Y, Cappa F, Avouac JP, Henry P, Elsworth D (2015) Seismicity triggered by fluid injections induced aseismic slip. Science 348(6240):1224-1226. https://doi.org/10. 1126/science.aab0476
Gutierrez M, Oino LE, Nygard R (2000) Stress-dependent permeability of a demineralised fracture in shale. Mar Pet Geol 17:895-907

Hacker BR (1997) Diagenesis and fault valve seismicity of crustal faults. J Geophys Res Solid Earth 102(B11):24459-24467. https://doi.org/10.1029/ 97JB02025

Ichenwo JL, Olatunji A (2018) Pore pressure and fracture pressure forecast in Niger Delta. Int J Eng Res Technol 7(4):338-344

Itasca F (2009) Fast Lagrangian analysis of continua in 3 dimensions, version 4.0. Minneapolis. Itasca Consulting Group, Minnesota, p 438

Jacquey A, Cacace M, Blöcher G, Scheck-Wenderoth M (2015) Numerical investigation of thermoelastic effects on fault slip tendency during injection and production of geothermal fluids. Energy Procedia 76:311-320. https://doi.org/ 10.1016/j.egypro.2015.07.868

Jaeger JC, Cook NG, Zimmerman R (2009) Fundamentals of rock mechanics. Wiley, London

Kanamori H, Abe K (1979) Reevaluation of the turn-of-thecentury seismicity peak. J Geophys Res 84(B11):6131-6139. https://doi.org/10.1029/ JB084iB11p06131

Kanamori H, Anderson DL (1975) Theoretical basis of some empirical relations in seismology. Bull Seismol Soc Am 65:1073-1095

Kanamori H, Brodsky EE (2001) The physics of earthquakes. Phys Today 54(6):34-40. https://doi.org/10.1063/1. 1387590

Kim S, Hosseini SA (2014) Geological $\mathrm{CO}_{2}$ storage: incorporation of pore-pressure/stress coupling and thermal effects to determine maximum sustainable pressure limit. Energy Procedia 63(2014):3339-3346

Lavrov A (2017) (2017) Fracture permeability under normal stress: a fully computational approach. J Pet Explor Prod Technol 7:181-194. https://doi.org/10.1007/s13202-0160254-6

Legarth B, Huenges E, Zimmermann G (2005) Hydraulic fracturing in a sedimentary geothermal reservoir: results and implications. Int J Rock Mech Min Sci 42(7):1028-1104

Liu W, Manga M (2009) Changes in permeability caused by dynamic stresses in fractured sandstone. Geophys Res Lett 36:L20307. https://doi.org/10.1029/2009GL039852

Mazzoldi A, Rinaldi AP, Borgia A, Rutqvist J (2012) Induced seismicity within geologic carbon sequestration projects: maximum earthquake magnitude and leakage potential. Int J Greenh Gas Control 10:434-442

Men X, Li J, Han Z (2018) Fracture propagation behavior of jointed rocks in hydraulic fracturing. Adv Mater Sci Eng. https://doi.org/10.1155/2018/9461284

Morris A, Ferrill DA, Henderson DB (1996) Slip-tendency analysis and fault reactivation. Geology 24(3):275-278

Nelson RA (1985) Geological analysis of naturally fractured reservoirs, 1st edn. Gulf Professional Publishing, Oxford

Norbeck J, Horne R (2015) Injection-triggered seismicity: an investigation of porothermoelastic effects using a rate-andstate earthquake model. In: PROCEEDINGS, fourtieth workshop on geothermal reservoir engineering Stanford University, Stanford, California 
Nwozor KK, Onuorah LO, Onyekuru SO, Egbuachor CJ (2017) Calibration of Gardner coefficient for density-velocity relationships of tertiary sediments in Niger Delta Basin. J Pet Explor Prod Technol 7(3):627-635. https://doi.org/ 10.1007/s13202-017-0313-7

Ogunsakin O, Ehinola AE, Olopade E (2019) Pressure regime, pressure regression detection and implications in the SMK field, Onshore, Western Niger Delta, Nigeria. Asian J Earth Sci 12(1):1-12. https://doi.org/10.3923/ajes.2019.1.12

Parker AC (2013) Modeling of seismic wave propagation through realistic and complex fracture networks. Idea League M.Sc. thesis, Delft University of Technology Department of Applied Geophysics and Petrophysics

Purcaru G, Berckhemer H (1982) Quantitative relations of seismic source parameters and a classification of earthquakes. Tectonophysics 84(1):57-128

Roberts PM (2005) Laboratory observations of altered porous fluid flow behavior in Berea sandstone induced by lowfrequency dynamic stress stimulation. Acoust Phys 51:140-148. https://doi.org/10.1134/1.2133962

Roberts PM, Abdel-Fattah AI (2009) Seismic stress stimulation mobilizes colloids trapped in a porous rock, Earth Planet. Sci Lett 284:538-543. https://doi.org/10.1016/j.epsl.2009. 05.017

Rutqvist J, Oldenburg C (2007) Analysis of cause and mechanism for injection-induced seismicity at the geysers geothermal field, California. GRC Trans 31:441-445

Rutqvist J, Wu YS, Tsang CF, Bodvarsson GA (2002) Modeling approach for analysis of coupled multiphase fluid flow, heat transfer, and deformation in fractured porous rock. Int J Rock Mech Min Sci 39:429-442

Rutqvist J, Rinaldi AP, Cappa F, Moridis GJ (2013) Modeling of fault reactivation and induced seismicity during hydraulic fracturing of shale-gas reservoirs. J Pet Sci Eng 107(2013):31-44. https://doi.org/10.1016/j.petrol.2013. 04.023

Rutqvist J, Rinaldi AP, Cappa F, Moridis GJ (2015) Modeling of fault activation and seismicity by injection directly into a fault zone associated with hydraulic fracturing of shale-gas reservoirs. J Pet Sci Eng 127(2015):377-386. https://doi. org/10.1016/j.petrol.2015.01.019

Schoenball M, Müller T, Müller B, Heidbach O (2010) Fluidinduced microseismicity in pre-stressed rock masses. Geophys J Int 180(2010):813-819

Scholz CH (2019) The mechanics of earthquakes and faulting, 3rd edn. Cambridge University Press, Cambridge. https:// doi.org/10.1017/9781316681473

Shrivastava C, Lawatia R (2011) Tight gas reservoirs: geological evaluation of the building blocks. In: SPE middle east unconventional gas conference and exhibition, 31 Jan-2 Feb, Muscat, Oman

Streit JE, Hillis RR (2004) Estimating fault stability and sustainable fluid pressures for underground storage of $\mathrm{CO}_{2}$ in porous rock. Energy 29(9-10):1445-1456

Tanikawa W, Sakaguchi M, Tadai O, Hirose T (2010) Influence of fault slip rate on shear-induced permeability. J Geophys Res 115:B07412. https://doi.org/10.1029/2009JB007013
Taron J, Elsworth D, Min K-B (2009) Numerical simulation of thermal-hydrologic-mechanical-chemical processes in deformable, fractured porous media. Int J Rock Mech Min Sci 46(5):842-854. https://doi.org/10.1016/j.ijrmms.2009. 01.008

Terzaghi K (1923) Die Berechnung der Durchlässigkeitsziffer des Tones aus dem Verlauf der hydrodynamischen Spannungserscheinungen (in German.). Sitz Akad Wissen Wien Math-Naturw Kl Abt IIa 132:105-124

Turner JP, Healy D, Hillis RR, Welch MJ (2017) Geomechanics and geology. Geological Society, London, Special Publications, 458, 7-29. First published online June 28, 2017, https://doi.org/10.1144/SP458.7

Vilarrasa V, Carrera J, Olivella S (2013) Hydromechanical characterization of $\mathrm{CO}_{2}$ injection sites. Int $\mathrm{J}$ Greenh Gas Control 19(2013):665-677

Wang H, Sharma MM (2019) Determine in-situ stress and characterize complex fractures in naturally fractured reservoirs from diagnostic fracture injection tests. Rock Mech Rock Eng. https://doi.org/10.1007/s00603-01901793-w

Wang R, Ding W, Zhang Y, Wang Z, Wang X, He J (2016) Analysis of developmental characteristics and dominant factors of fractures in lower Cambrian marine shale reservoirs: a case study of Niutitang formation in cen'gong block, southern China. J Pet Sci Eng 138:31-49

Warren JE, Root PJ (1963) Root PJ (1963) The behavior of naturally fractured reservoirs. Soc Pet Eng J 3(03):245-255. https://doi.org/10.2118/426-pa

Watkins H, Healy D, Bond CE, Butler RWH (2018) Implications of heterogeneous fracture distribution on reservoir quality; an analogue from the Torridon Group sandstone, Moine Thrust Belt, NW Scotland. J Struct Geol 108(2018):180-197. https://doi.org/10.1016/j.jsg.2017.06. 002

White MD, Podgorney R, Kelkar SM, McClure MW, Danko G, Ghassemi A, Fu P, Bahrami D, Barbier C, Cheng Q, Chiu KK (2016) Benchmark problems of the geothermal technologies office code comparison study (No. PNNL-26016). Pacific Northwest National Lab, Richland

Xue YC, Cheng LS, Mou JY, Zhao WA (2014) New fracture prediction method by combining genetic algorithm with neural network in low-permeability reservoirs. J Pet Sci Eng 121:159-166

Yang Y, Zoback MD (2014) The role of pre-existing fractures and faults during multistage hydraulic fracturing in the Bakken formation. Interpretation 2(3):SG25-SG39. https://doi.org/10.1190/INT-2013-0158.1

Zhang Z, He S, Gu D, Gai S, Li G (2018) Effects of stressdependent permeability on well performance of ultra-low permeability oil reservoir in China. J Pet Explor Prod Technol 8:565-575. https://doi.org/10.1007/s13202-0170342-2

Publisher's Note Springer Nature remains neutral with regard to jurisdictional claims in published maps and institutional affiliations. 